\title{
Changing suspended sediment in United States rivers and streams: linking sediment trends to changes in land use/cover, hydrology and climate
}

\author{
Jennifer C. Murphy \\ US Geological Survey, Lower Mississippi-Gulf Water Science Center, Nashville, Tennessee, USA
}

Correspondence: Jennifer C. Murphy (jmurphy@usgs.gov)

Received: 20 August 2019 - Discussion started: 20 September 2019

Revised: 16 January 2020 - Accepted: 27 January 2020 - Published: 3 March 2020

\begin{abstract}
Sediment is one of the leading pollutants in rivers and streams across the United States (US) and the world. Between 1992 and 2012, concentrations of annual mean suspended sediment decreased at over half of the 137 stream sites assessed across the contiguous US. Increases occurred at less than $25 \%$ of the sites, and the direction of change was uncertain at the remaining $25 \%$. Sediment trends were characterized using the Weighted Regressions on Time, Discharge, and Season (WRTDS) model, and decreases in sediment ranged from $-95 \%$ to $-8.5 \%$ of the 1992 concentration. To explore potential drivers of these changes, the sediment trends were (1) parsed into two broad contributors of change, changes in land management versus changes in the streamflow regime, and (2) grouped by land use of the watershed and correlated to concurrent changes in land use or land cover (land use/cover), hydrology and climate variables and static/long-term watershed characteristics. At $83 \%$ of the sites, changes in land management (captured by changes in the concentration-streamflow relationship over time; C$\mathrm{Q}$ relationship) contributed more to the change in the sediment trend than changes in the streamflow regime alone (i.e., any systematic change in the magnitude, frequency or timing of flows). However, at $>50 \%$ of the sites, changes in the streamflow regime contributed at least a $5 \%$ change in sediment, and at 11 sites changes in the streamflow regime contributed over half the change in sediment, indicating that at many sites changes in streamflow were not the main driver of changes in sediment but were often an important supporting factor. Correlations between sediment trends and concurrent changes in land use/cover, hydrology and climate were often stronger at sites draining watersheds with more homogenous, human-related land uses (i.e., agricultural and
\end{abstract}

urban lands) compared to mixed-use or undeveloped lands. At many sites, decreases in sediment occurred despite smallto-moderate increases in the amount of urban or agricultural land in the watershed, suggesting conservation efforts and best-management practices (BMPs) used to reduce sediment runoff to streams may be successful, up to a point, as lands are converted to urban and agricultural uses.

\section{Introduction}

Across the United States (US) and the world, sediment is one of the leading pollutants in rivers and streams (USEPA, 2008-2016; Walling, 2009), degrading aquatic habitats and affecting water usability (Brown and Froemke, 2012; Wohl, 2015). River monitoring programs of sediment are typically implemented to collect data to characterize status and temporal changes in the delivery of suspended material, often with an explicit goal of capturing improvements. An implicit goal of many of these programs is a better understanding of why sediment delivery has or has not varied over time (Irvine et al., 2015). To optimize the ability to characterize and detect temporal changes, many monitoring programs focus on implementing the best sampling design. A missing piece is often the observation and characterization of potential drivers of these changes in sediment (Irvine et al., 2015), such as shifts in land use or land cover (land use/cover), changes in management of the landscape or stream, or climatic variability.

There are multiple approaches for linking changes in sediment at stream sites with changes in land use/cover, hydrol- 
ogy and climate. These approaches include using qualitative statements with or without data (e.g., Gao et al., 2013; Kreiling and Houser, 2016; Li et al., 2016), using processbased watershed and landscape models (e.g., Ficklin et a., 2013; Lacher et al., 2019), and teasing apart water-quality and streamflow records to identify and estimate the amount of change due to human actions, climate or hydrology (e.g., Gao et al., 2013; Li et al., 2016; Murphy and Sprague, 2019; Choquette et al., 2019; Rossi et al., 2009). Many of these approaches are hindered by the lack of available data that characterize potential drivers of change. Such data are often not available or not available across many sites. Some studies have used geospatial data to generate estimates of various land use and land disturbance metrics and have been successful at linking these to spatial variations in static water-quality conditions (e.g., Mehaffey et al., 2005; Carey et al., 2011). Using static land use conditions (either current or long-term average conditions) and recent water-quality conditions provides information about spatial variability but does not explicitly explore how temporal changes in land use/cover or other human activities affect water quality. Other studies have begun to explore the effect of temporal changes on water quality by explicitly considering land use/cover, land management and hydrologic changes over time using empirical approaches such as structural equation models (Ryberg, 2017; Ryberg et al., 2018), hybrid deterministic-empirical approaches (Chanat and Yang, 2018) or focusing on a couple of specific potential causes in a limited geographic area (Schottler et al., 2014; Panthi et al., 2017). Historically, fieldbased assessments in specific areas have been successful at identifying and supporting a causal understanding of changes in river sediment (e.g., Wolman and Schick, 1967; Trimble and Lund, 1982; Gellis et al., 1991).

At many sites, concentrations (or loads) of annual mean sediment covary with annual streamflow conditions. Much of this year-to-year variability in streamflow is dependent on weather, though at some locations there may be a longer-term systematic change in streamflow that also influences sediment. Thus, for a given year, annual mean concentrations of sediment are a function of the streamflow conditions for that year, changes that occurred in the watershed (i.e., land management activities, surface or channel disturbance, etc.) and, at some locations, a systematic change in some portion of the streamflow regime (Murphy and Sprague, 2019; Choquette et al., 2019). When trying to understand potential drivers of long-term changes in sediment, it is the influence of land management changes and systematic changes in streamflow that are of most interest.

All rivers have a characteristic streamflow regime that captures the typical pattern of fluctuations in the magnitude, timing and frequency of streamflow across a given year. Individual years may be wetter or drier due to variations in weather, but under a stationary climate and limited human influences, these fluctuations are within expected ranges for a given streamflow regime. And as mentioned above, these year-to- year fluctuations are of less interest when trying to understand multi-year and multi-decade changes in water quality. However, systematic changes in the streamflow regime over time caused by natural and anthropogenic influences, such as increases in precipitation or a change in dam operations, are important when trying to understand long-term water-quality changes. Changes in the streamflow regime can occur in many forms, such as increases in mean streamflow, decreases in the frequency of high streamflow events or a shift in high streamflow from spring to winter. Changes in the streamflow regime may ultimately lead to changes in sediment concentrations in a stream because of shifts in transport processes or changes in which channel or near-channel sediment sources are eroded. This can include geomorphological changes like increased head cutting and channel bank sloughing, as well as channel bottom scouring and resuspension.

The effect of streamflow-related changes on sediment can be compared to changes in sediment resulting from management and disturbance on the landscape. Changes in land management (including surface disturbance and other human actions in the watershed) may enhance or try to minimize the sediment available for transport to a stream via overland runoff. For example, increases in the amount of land used for grazing or crops, increased construction in suburban or exurban areas, and increases in mining or harvesting of timber can all lead to enhanced erosion. However, other management actions, such as agricultural conservation practices, urban bestmanagement practices (BMPs), the enrollment of agricultural land in the Conservation Reserve Program (CRP) and channel restoration efforts attempt to reduce erosion or trap eroded sediment. CRP mitigation measures include paying farmers to remove environmentally sensitive land from production and plant erosion-controlling and ecologically beneficial plants instead. Attributing sediment trends to these broad categories of change (i.e., land management versus the streamflow regime) provides a means for better understanding the relative influence of largely controllable human influences on sediment in streams, resulting from changes in land management and surface disturbance, compared to the influence of less controllable changes in the streamflow regime.

In this paper, an extensive dataset of temporal changes in land use/cover, hydrology and climate is used in conjunction with 2 decades of sediment and streamflow data to characterize changes in annual mean concentrations of suspended sediment (SSC) and total suspended solids (TSS; hereafter referred to collectively as sediment) and explore potential drivers of these changes at 137 stream sites across the contiguous US. The objectives are to (1) summarize and describe sediment trends between 1992 and 2012; (2) explore contributions to sediment trends from changes in land management versus changes in the streamflow regime; and (3) link specific land use/cover changes, hydro-climatic changes, and static and long-term watershed characteristics to sediment trends. This paper builds off the insights presented in Murphy and Sprague (2019) by explicitly exploring contribu- 
tions from changes in land management versus changes in the streamflow regime for sediment, regionally and by land use. It also goes beyond the analysis presented in Murphy and Sprague (2019) by exploring changes in overall sediment across the US and how these changes in sediment vary regionally and with land use and linking these sediment changes to observed changes in land use/cover, streamflow and climate. The overarching goals of this effort are to better understand how sediment concentration has changed over time across the US and to provide insight into the potential drivers of these trends.

\section{Methods}

\subsection{Description of water-quality data and trend results}

This study relied on the water-quality data and trend analyses described in Oelsner et al. (2017), a comprehensive waterquality and ecology trend assessment of US rivers, spanning four trend periods beginning as early as 1972. With nearly 12000 reported trend results for approximately 1500 sites, the focus of their publication was to document data acquisition, harmonization and screening processes and the trend analysis methods. The trend results and data were published in De Cicco et al. (2017) and Murphy et al. (2018). The data originated from 74 federal, state and local governments and organizations that collect and process stream water-quality samples across the contiguous US. Each site was associated with a streamflow gage. For this paper, the 1992-2012 sediment trends (annual estimates and changes) were extracted from Murphy et al. (2018), and sites with drainage areas $<300000$ square kilometers $\left(\mathrm{km}^{2}\right)$ were retained; 7 sites that had very large drainages ranging from 410000 to $1080000 \mathrm{~km}^{2}$ were excluded. An additional site, on the Atchafalaya River in Louisiana (site no. 07381495), was also excluded because a large proportion of the water at this site is diverted from an adjacent watershed. The extracted sediment trends included results for SSC and TSS concentration, at 99 sites and 41 sites, respectively. A few sites $(n=3)$ had data and trends for both parameters, resulting in 137 unique sites overall. All analyses were completed using the R statistical software program (R Core Team, 2018).

SSC and TSS characterize suspended material in the river column, but these estimates are not directly comparable and must be interpreted somewhat differently. ASTM Standard Test Method D 3977-97 was used for SSC determinations (American Society for Testing and Materials, 2000), and Method 2540 D, with some variations (Gray et al., 2000), was used for TSS determinations (American Public Health Association et al., 1995). The difference in SSC and TSS determinations is largely due to differences in the watersample preparation procedures, resulting in different suspended particle-size distributions for the same water sample. The comparability of these sediment parameters is de- scribed in Gray et al. (2000) and briefly summarized here. SSC is determined by measuring the dry weight of all sediment from a water sample of a known volume. Several techniques are used to determine TSS, and most techniques similarly measure the dry weight of all sediment from a water sample of a known volume; however, this technique as defined by the TSS protocol (American Public Health Association et al., 1995) weighs the sediment in only a $100 \mathrm{~mL}$ sub-sample from the original water sample. Due to the physical properties of sediment and water, taking an aliquot of the original water sample tends to leave larger particle sizes (often sands) in the original sample. Thus, TSS generally characterizes only finer suspended particle sizes, whereas SSC characterizes the entire suspended particle-size distribution of the original sample and presumably the river. The downward bias of TSS compared to SSC, especially at sites with larger proportions of sand-sized sediment, is an important consideration when interpreting changes in TSS or comparing TSS to SSC. Both parameters are reported here because SSC determinations are more accurate, reliable and presumably characterize the entire suspended particle-size distribution of the sampled stream, whereas TSS determinations are much more common across the US.

Oelsner et al. (2017) and Murphy et al. (2018) provide a complete description of the modeling specifications used to generate trends presented in this study. Briefly, the Weighted Regressions on Time, Discharge, and Season model (WRTDS; original: Hirsch et al., 2010; updates: Choquette et al., 2019) was used to calculate trends between 1992 and 2012. For each site and parameter, WRTDS uses weighted regression to estimate daily mean concentrations. These estimated daily concentrations are flow normalized (FN) to remove the influence of year-to-year variability from streamflow, which is mostly weather-driven, and the non-FN and FN daily estimates are separately aggregated to non-FN and FN annual mean concentrations. Flow normalization is an approach for identifying the "signal" of long-term systematic water-quality changes due to human actions on the landscape from the "noise" of high year-toyear variability. This process provides estimates of concentration that exclude effects of year-to-year fluctuations in streamflow, due largely to variability in weather, but it retains the effects from both seasonal streamflow variability and long-term, systematic streamflow trends, both of which may influence long-term systematic changes in water quality (Choquette et al., 2019). Trends are reported as the time series of FN annual values and as the change (in both milligrams per liter, $\mathrm{mg} \mathrm{L}^{-1}$, and percent change relative to initial concentrations) between the 1992 and 2012 FN sediment concentration. Thus, the 1992-2012 trend was calculated as (FN2012 - FN1992) / FN1992 × 100. See Hirsch et al. (2010) and Choquette et al. (2019) for a complete description of the trend methods, including the weighted regression approach and the flow-normalization process. These analyses were completed using the EGRET version 3.0 R pack- 
age (Hirsch et al., 2018a). Furthermore, to gauge the uncertainty of the trends, likelihood estimates of the trend direction for each site and parameter were extracted from Murphy et al. (2018). A block-bootstrapping approach was used and is presented in Hirsch et al. (2015) and further refined in Hirsch et al. (2018b). The modeling specifications for deriving these estimates are described in Oelsner et al. (2017) and Murphy et al. (2018). Upward or downward trends were considered "likely" if the likelihood was $>0.85$, "somewhat likely" if the likelihood was from 0.85 to 0.70 , and "as likely as not" to be upward or downward if the likelihood was $<0.70$. See the Supplement for additional explanation of trend methods. The efficacy of using WRTDS for estimating trends in sediment concentration and flux has been explored and discussed in Moyer et al. (2012), Chanat et al. (2016), and Lee et al. (2016).

\subsection{Description of watershed data and changes}

For each site, 44 variables of land use/cover change, hydro-climatic-change and static/long-term watershed characteristics (Table 1) were generated or compiled using data from Falcone (2017) and Farmer et al. (2017). Falcone (2017) includes time series variables characterizing land use/cover and climate for each watershed. When possible, land use/cover variables were also generated for a near-site, near-stream zone, which were computed as $25 \%$ of the watershed area nearest the site and stream (Fig. S1 in the Supplement), and this is hereafter referred to as the proximal zone. For this study, the percent change, relative to the starting condition, of each variable was calculated using the years closest to 1992 and 2012, i.e., (variable2012 - variable1992) / variable1992 $\times 100$. The spatial resolution and frequency of data collection varied by variable. Data collected at the annual timescale were smoothed using locally weighted regression (loess) prior to calculating percent change to characterize the systematic change in these variables over time. Loess smoothing was completed using the loess function in $\mathrm{R}$ with the span argument set to 0.75 , meaning $75 \%$ of the years were used in each window. The static/long-term watershed characteristics were also extracted from Falcone (2017). Three variables characterizing trends in streamflow were retrieved from Farmer et al. (2017) for each site. See Table 1 for a list of variables and brief descriptions; also, see the Supplement for additional proximalzone variables. See Falcone (2017) and Farmer et al. (2017) for specific information about data processing and the original source information for these data.

Each site was assigned to one of four categories describing the predominant land use in the corresponding watershed (urban, agricultural, undeveloped or mixed-use), based on the categorization scheme provided in Falcone (2015). See Supplement for the explicit land use categorization scheme used in this study. Across all 137 sites with either SSC or TSS data, seven sites switched land use categories between 1992 and 2012. All seven watersheds became more urban, shifting categories from mixed-use, agricultural or undeveloped to urban or mixed-use. For consistency, and because the specific reason(s) that caused a site to switch land use categories presumably corresponds to the land use category at the end of the record (e.g., increased urbanization caused an agricultural watershed to become an urban watershed), the 2012 land use categorization was used to group sites.

\subsection{Methods for exploring potential drivers of change}

Since the potential drivers of systematic, multi-decadal changes in sediment in US rivers and streams are varied, one useful approach is to conceptualize changes in sediment as a function of changes in the streamflow regime and changes on the landscape (Choquette et al., 2019; Murphy and Sprague, 2019). Thus, each sediment trend was parsed into two components of change: the amount of change due to changes in the streamflow regime, i.e., the streamflow trend component (QTC), and the amount of change in sediment due to changes in land management, i.e., the management trend component (MTC). These estimates, which can be found in Murphy et al. (2018), were compared across watershed land uses, geographic regions and sediment trend magnitudes. Choquette et al. (2019), Hirsch et al. (2018a), and Murphy and Sprague (2019) provide details about the method used to parse water-quality trends into QTC and MTC contributions.

Briefly, the sediment trend can be described as an additive function of MTC and QTC, the absolute and relative contributions of which provide insight into broad drivers of change (Choquette et al., 2019; Murphy et al., 2019). MTC is estimated as the sediment trend assuming a stationary streamflow regime. As such, MTC describes the potential amount of change in sediment concentrations over time due to factors other than long-term systematic changes in the streamflow regime. This estimate isolates the amount of change in sediment due to changes in the concentration-streamflow (C-Q) relationship (Choquette et al., 2019; Murphy and Sprague, 2019), also often referred to as a sediment rating curve. Changes in $\mathrm{C}-\mathrm{Q}$ relationships are often used to identify and understand human influences on water quality (e.g., Moatar et al., 2017; Murphy et al., 2014; Basu et al., 2010; Bieroza et al., 2018). Choquette et al. (2019) and Hirsch et al. (2018a) refer to MTC as CQTC (concentration-streamflow trend component), but this analysis uses the more conceptual terminology presented by Murphy and Sprague (2019). Analytically, MTC is estimated using WRTDS with a stationary streamflow regime specified during the flow-normalization procedure. MTC is subtracted from the sediment trend to give QTC. QTC describes the potential amount of change in sediment concentrations over time due specifically to longterm, sustained changes in any aspect of the streamflow regime. These could be changes in the magnitude, timing or frequency of streamflow that ultimately effect sediment. Taken together, the sediment trend is the sum of MTC and 
Table 1. Land use/cover and hydro-climatic-change variables and static/long-term watershed characteristics used in correlation analyses. Streamflow trend variables ("Q slope: mean day", "Q slope: max day" and "Q slope: 7 d min") are from Farmer et al. (2017); all other variables are published in Falcone (2017); see publications for details and original source information. Symbols \#\# and \#\#\#\# in variable names indicate the two-digit or four-digit year of data value. Percent-change computations are (trend end year value - trend start year value) / trend start year value $\times 100$, using years closest to 1992 and 2012, unless otherwise noted (square kilometers, km ${ }^{2}$; meters, m; centimeters, cm; degrees Celsius, $\left.{ }^{\circ} \mathrm{C}\right)$.

\begin{tabular}{|c|c|}
\hline Short name & Data description (original time series or static variable name from referenced source) \\
\hline \multicolumn{2}{|l|}{ Land use/cover changes ${ }^{\mathrm{a}}$} \\
\hline Agricultural land & $\begin{array}{l}\text { Percent change in agricultural land, excluding potential grazing lands, as a percentage of the } \\
\text { watershed (NWALT\#\#_AG4344_SUM) }\end{array}$ \\
\hline Ag+grazing land & $\begin{array}{l}\text { Percent change in agricultural land, including potential grazing lands, as a percentage of the } \\
\text { watershed (NWALT\#\#_AG4346_SUM) }\end{array}$ \\
\hline Cropped land & Percent change in row-cropped land as a percentage of the watershed (NWALT\#\#_43) \\
\hline $\mathrm{Ag}$ land in CRP & $\begin{array}{l}\text { Percent change in proportion of agricultural land enrolled in the Conservation Reserve } \\
\text { Program across the watershed (crp.crop\#\#) }\end{array}$ \\
\hline Watershed in CRP & $\begin{array}{l}\text { Percent change in amount of land enrolled in the Conservation Reserve Program as a percentage } \\
\text { of the watershed (NWALT\#\#_AG4344_SUM } \times \text { crp.crop\#\# } \times 0.01 \text { ) }\end{array}$ \\
\hline Proximal-zone ag land in CRP & $\begin{array}{l}\text { Percent change in proportion of agricultural land enrolled in the Conservation Reserve } \\
\text { Program in the proximal zone }{ }^{\text {b }} \text { (RIP_NRSITE_CRP_CROP\#\#) }\end{array}$ \\
\hline Proximal zone in CRP & $\begin{array}{l}\text { Percent change in amount of land enrolled in the Conservation Reserve Program as a percentage } \\
\text { of the proximal zone } \\
(\text { RIP_NRSITE_NWALT\#\#_AG4344_SUM } \times \text { RIP_NRSITE_CRP_CROP\#\# × 0.01) }\end{array}$ \\
\hline All developed land & $\begin{array}{l}\text { Percent change in developed and semi-developed land as a percentage of the watershed } \\
\text { (NWALT\#\#_DEV_SUM + NWALT\#\#_SEMIDEV_SUM) }\end{array}$ \\
\hline Developed land & Percent change in developed land as a percentage of the watershed (NWALT\#\#_DEV_SUM) \\
\hline Semi-developed land & $\begin{array}{l}\text { Percent change in semi-developed land (land in close proximity to developed lands and partially } \\
\text { used for the same purposes) as a percentage of the watershed (NWALT\#\#_SEMIDEV_SUM) }\end{array}$ \\
\hline Impervious area & Percent change in impervious land cover as a percentage of the watershed (NWALT_IMPV\#\#) \\
\hline Low-med-density dwellings & $\begin{array}{l}\text { Percent change in land with low-medium-density residential development as a percentage } \\
\text { of the watershed (NWALT\#\#_26) }\end{array}$ \\
\hline Low-use land & $\begin{array}{l}\text { Percent change in land with little-to-no development or agriculture as a percentage of the } \\
\text { watershed (NWALT\#\#_50+NWALT\#\#_60) }\end{array}$ \\
\hline Forest since '02 & $\begin{array}{l}\text { Percent change in forested land between } 2002 \text { and } 2012 \text { as a percentage of the watershed } \\
\text { (CDLXXXX_PCT_141+CDLXXXX_PCT_142+CDLXXXX_PCT_143) }\end{array}$ \\
\hline Cumulative timber & $\begin{array}{l}\text { Cumulative sum of the percent of the watershed with timber or forest cutting for years since } \\
1999 \text { (timber_\#\#\#\#) }\end{array}$ \\
\hline \multicolumn{2}{|l|}{ Hydro-climatic changes } \\
\hline Total precip & $\begin{array}{l}\text { Percent change in total precipitation across the watershed (sum of monthly mean precipitation; } \\
\text { see Falcone, 2017) }\end{array}$ \\
\hline Average temp & $\begin{array}{l}\text { Percent change in annual mean monthly temperature across the watershed (mean of monthly } \\
\text { mean temperature; see Falcone, 2017) }\end{array}$ \\
\hline Temp range & $\begin{array}{l}\text { Percent change in monthly mean temperature range across the watershed (difference between } \\
\text { hottest and coldest monthly mean temperature of the same year; see Falcone, 2017) }\end{array}$ \\
\hline Max temp & $\begin{array}{l}\text { Percent change in annual maximum monthly temperature across the watershed (maximum of } \\
\text { monthly mean temperature, see Falcone, 2017) }\end{array}$ \\
\hline Q slope: mean day & $\begin{array}{l}\text { Slope of annual mean daily streamflow trend as percent change per year } \\
\left(\left(\mathrm{e}^{\wedge} \text { meanL_slope }-1\right) \times 100\right)\end{array}$ \\
\hline
\end{tabular}


Table 1. Continued.

\begin{tabular}{|c|c|}
\hline Short name & Data description (original time series or static variable name from referenced source) \\
\hline Q slope: max day & $\begin{array}{l}\text { Slope of annual maximum daily streamflow trend as percent change per year } \\
\left(\left(\mathrm{e}^{\wedge} \text { maxL_slope }-1\right) \times 100\right)\end{array}$ \\
\hline Q slope: $7 \mathrm{~d} \min$ & $\begin{array}{l}\text { Slope of annual } 7 \mathrm{~d} \text { minimum streamflow trend as percent change per year } \\
\left(\left(\mathrm{e}^{\wedge} \min 7 \mathrm{~nL} \_ \text {slope }-1\right) \times 100\right)\end{array}$ \\
\hline Density of major dams & $\begin{array}{l}\text { Percent change in the number of major dams per } 100 \mathrm{~km}^{2} \text { across the watershed } \\
\text { (MAJDAMS_100sqkm_\#\#\#\#) }\end{array}$ \\
\hline Dam storage & Percent change in dam storage per $\mathrm{km}^{2}$ across the watershed (NORMSTOR_sqkm_\#\#\#\#) \\
\hline \multicolumn{2}{|c|}{ Static/long-term watershed characteristics } \\
\hline Drainage area & Drainage area of the watershed, in square kilometers (gisareakm2) \\
\hline Basin compactness & $\begin{array}{l}\text { Watershed compactness ratio (area/perimeter }{ }^{\wedge} 2 \times 100 \text { ), higher number means more compact } \\
\text { (circular) shape, unitless (bas_compactness) }\end{array}$ \\
\hline Average elevation & Mean watershed elevation, in meters (ELEV_SITE_M) \\
\hline SD of elevation & Standard deviation of elevation across watershed, in meters (ELEV_STD_M_BASIN) \\
\hline Proportion canals/pipes & Proportion of flow lines that are canals, ditches or pipes, unitless (prop_canals_pipe) \\
\hline Percent tile drains & Estimate of percent of the watershed drained by tile drains in 2012 (CPRAC_tiledrains) \\
\hline Percent conservation tillage & $\begin{array}{l}\text { Estimate of percent of the watershed with conservation tillage in } 2012 \\
\text { (CPRAC_conservation_till) }\end{array}$ \\
\hline Percent forest in 2012 & $\begin{array}{l}\text { Percent of the watershed with forest in } 2012 \\
\text { (CDL2012_PCT_141 + CDL2012_PCT_142 + CDL2012_PCT_143) }\end{array}$ \\
\hline
\end{tabular}

Percent proximal-zone forest in Percent of the proximal zone with forest in 2012 (RIP_NRSITE_NLCDXX_FOREST) ${ }^{\mathrm{b}}$ 2012

Long-term average precip Mean annual precipitation for the watershed, using 1981-2010 record, in centimeters (PPT_AVG_8110)

Long-term average temp Mean annual air temperature for the watershed, using 1981-2010 record, in degrees Celsiu (T_AVG_8110)

Long-term relative humidity Mean relative humidity for the watershed, using 1961-1990 record, in percent (RH_AVG)

Base flow index Base flow index, which is the ratio of base flow to total streamflow, in percent (BFI_AVE)

Percent clay Percent of the watershed with clay soils (CLAYAVE)

Average permeability Average permeability, in inches per hour (PERMAVE; multiply by 2.54 for centimeters per hour)

Erosion potential $\mathrm{K}$ factor from the Universal Soil Loss Equation, higher values mean greater potential for erosion, unitless (KFACT_UP)

Era of first dev, watershed $\quad$ Era of first development, i.e., a measure of if the area was developed a long time ago or recently; original values from Falcone (2017) converted to decimal decade (e.g., 2000.75 means the first development occurred about three quarters of the way through the decade beginning in 2000 , i.e., circa 2007; note that 1940 means 1940 or earlier) (ERA_FIRSTDEV)

\begin{tabular}{ll}
\hline Era of first dev, proximal zone & $\begin{array}{l}\text { b } \\
\text { (RIP_NRSITE_ERA_FIRSTDEV) }\end{array}$ \\
\hline Major dam density in 2013 & Number of major dams per $100 \mathrm{~km}^{2}$ across watershed in 2013 (MAJDAMS_100sqkm_2013) \\
\hline Dam storage in 2013 & $\begin{array}{l}\text { Dam storage across watershed in } 2013 \text {, in acre feet per } 100 \mathrm{~km}^{2} \\
\text { (NORMSTOR_sqkm_2013; multiply by } 1233.48 \text { for cubic meters per } 100 \text { square kilometers) }\end{array}$
\end{tabular}

${ }^{a}$ All land use variables are rounded to $1 \%$ of the watershed or proximal-zone area prior to calculating percent change. ${ }^{b}$ Variables not included in Falcone (2017) and estimated for this study using the same procedures described in Falcone (2017). 
QTC. See the Supplement for more information. Also, see Choquette et al. (2019), Hirsch et al. (2018a), and Murphy and Sprague (2019) for a complete description of these methods including example applications at individual sites and extended discussion on interpreting these types of estimates. Additionally, while Murphy and Sprague (2019) present estimates of MTC and QTC for sediment at some of the same sites in this paper (though for a longer trend period), the results presented here greatly expand that initial investigation by comparing these estimates regionally, by land use, to the magnitude of the overall change in sediment and to observed land use/cover changes, hydro-climatic-changes and static/long-term watershed characteristics.

Finally, to link sediment trends to specific changes in land use/cover, hydrology and climate, as well as static/long-term watershed characteristics that might influence how responsive a site is to change, a correlation analysis was completed. The Kendall's tau correlation coefficient (Kendall, 1938) was computed between the sediment trend, in percent change and each of the 24 potential causal variables (15 land use/cover and 9 hydro-climatic changes, Table 1). For correlations with the 20 static/long-term watershed characteristics (Table 1), the sediment trend in absolute percent change was used. These potential causal variables were selected because they characterize or serve as a proxy for possible drivers of change, and the available data were temporally and spatially consistent. The static/long-term watershed characteristics describe various physical features of the watershed that could influence the sensitivity of sediment at a site to changes in the watershed. Kendall's tau is a non-parametric alternative to Pearson's correlation and was used because of the nonnormal distributions of the variables.

\section{Results and discussion}

\subsection{Sediment concentration trends}

In the 2 decades following 1992, sediment concentrations largely decreased at the 137 rivers and stream sites across the contiguous US. Downward trends were more common and had larger magnitudes for SSC trends compared to TSS trends (Table 2), and sites with the highest starting concentrations tended to have decreases in sediment, regardless of the sediment parameter (Fig. S3). Starting concentrations were typically lower for TSS compared to SSC (Table 2), reflecting a combination of differences in analytical procedures and different sets of sites.

Decreasing sediment trends were widespread across the US with increasing concentrations occurring in localized clusters of sites (Fig. 1). Increases in SSC occurred only at sites in the eastern US (Fig. 1), where the median percent change across these sites was $5 \%$. SSC sites in the western and central US had large decreases in sediment (median changes of $-45 \%$ and $-23 \%$, respectively; Fig. 2a).
Increases in TSS occurred at sites across all geographic regions (Fig. 1) with a pronounced cluster of sites, with a median increase of $18 \%$, in the western US (Fig. 2a). These differences in the geographic distribution of SSC and TSS sites are an important consideration for understanding potential drivers of sediment trends.

Like other studies, categorization of sites by the land use of their contributing watershed yielded different patterns of sediment trends (Oelsner and Stets, 2019; Lacher et al., 2019). Agricultural, urban and mixed-use watersheds tended to have larger proportions of sites with decreasing sediment (Fig. 2b). Undeveloped sites had large decreases in SSC but increases in TSS, with median changes of $-41 \%$ and $15 \%$, respectively (Fig. 2b). This marked difference in trend direction between SSC and TSS at undeveloped sites may be due to different changes in land management between these groups of sites (explored in more detail below), but they may also be due to other contributing factors such as differences in the suspended particle-size distributions being characterized by SSC and TSS or different underlying geology between these groups of sites. These factors may also interact. For example, many of the undeveloped TSS sites are in the northwestern US (Fig. S4), underlain by volcanic and metamorphic geology with steep terrain. These geologic features likely result in streams transporting larger particle sizes, a situation where TSS provides less accurate estimates of sediment.

\subsection{Land management changes}

Murphy and Sprague (2019) showed that MTC is typically the dominant contributor to trends in concentration for sediment and other water-quality parameters such as nutrients, major ions and salinity. This study, which uses a shorter trend period than Murphy and Sprague (2019), found $83 \%$ of the sediment trends had larger absolute values of MTC than QTC (Table 3). This pattern held across all land use categories and most sites individually (Fig. S5, Table 3), indicating that changes in land management typically had a greater influence on sediment transport than changes in the streamflow regime alone. Furthermore, MTCs tended to be negative, mirroring the overall sediment trend (Fig. 3a). Many studies using a variety of approaches have also shown changes in land management and/or land use/cover to be a major driver of changes in sediment over time (e.g., Lacher et al., 2019; Li et al., 2016; Vogl and Lopes, 2010; Kreiling and Houser, 2016; Gitau et al., 2010; Panthi et al., 2017).

Changes in MTC, which are analytically changes in the $\mathrm{C}-\mathrm{Q}$ relationship, are a common tool used by researchers and watershed managers to gauge the influence of conservation practices and management changes on water quality. For example, in the highly urban Delaware River basin in the northeastern US, the Delaware River Basin Commission uses changes in the $\mathrm{C}-\mathrm{Q}$ relationship as one of several ways to detect "measurable change to existing water quality" (Lim- 
Table 2. SSC and TSS trends from 1992 to 2012. Rows for starting concentration, concentration change and percent change show minimum - maximum (mean) rounded to two significant figures (SSC, suspended-sediment concentration; TSS, total suspended-solid concentration; no., number; conc, concentration; $\mathrm{mg} \mathrm{L}^{-1}$, milligrams per liter).

\begin{tabular}{lll}
\hline & SSC & TSS \\
\hline Number of sites & 41 & 99 \\
Starting conc & 4.4 to $870(140)$ & 1.1 to $270(45)$ \\
Conc change $\left(\mathrm{mg} \mathrm{L}^{-1}\right)$ & -410 to $72(-51)$ & -83 to $40(-9.1)$ \\
Conc percent change & -95 to $61(-25)$ & -64 to $200(-6.3)$ \\
Percent change for upward trends & 5.8 to $61(31)$ & 13 to $200(47)$ \\
Percent change for downward trends & -95 to $-11(-43)$ & -64 to $-8.5(-31)$ \\
Percent change for uncertain trends & -5.1 to $10(4.3)$ & -8.7 to $30(2.7)$ \\
No. of upward ${ }^{1}$ trends (percent of sites) & $4(9.8 \%)$ & $20(20 \%)$ \\
No. of downward ${ }^{1}$ trends (percent of sites) & $28(68 \%)$ & $53(53 \%)$ \\
No. of uncertain ${ }^{2}$ trends (percent of sites) & $9(22 \%)$ & $26(26 \%)$ \\
\hline${ }^{1}$ Includes likelihoods $\geq 0.70$ (trend is "likely" and "somewhat likely" upward or downward). ${ }^{2}$ Only likelihoods \\
$<0.70$ (trend is "as likely as not" to be upward or downward; i.e., trend direction is uncertain).
\end{tabular}

beck et al., 2016). Similarly, Moatar et al. (2017) used C-Q relationships to characterize the effect of changes in point sources on water quality across streams in Europe. About $80 \%$ of the SSC trends and $60 \%$ of the TSS trends had negative MTCs, suggesting that, at many sites, management actions on the landscape may have had the desired effect of decreasing sediment concentration in local streams (Table 3 ).

Sediment trends were moderately to strongly correlated (abs $(\operatorname{tau})>0.4$; absolute) with several specific changes in land use/cover, depending on the land use of the watershed and the sediment parameter (Fig. 4). Watersheds that had more anthropogenic and homogenous land uses tended to have higher correlations between SSC trends and specific land use/cover change variables. For example, SSC trends at urban sites were well correlated with five variables, indicative of urbanization, and at agricultural sites SSC trends were well correlated with six variables characterizing changes in agriculture or moderate development (Fig. 4). Undeveloped and mixed-use sites were well correlated with fewer land use/cover change variables. Note that many of the moderateto-strong correlations between potential drivers of change and SSC trends were not statistically significant at the 0.05 level due to a variety of reasons, one of which is likely the small number of sites in some of the land use categories.

In general, TSS trends were not well correlated with many of the land use/cover change variables (Fig. 4). The lack of well-correlated variables may be due to the uncertainty introduced during TSS determinations (Gray et al., 2000) as opposed to a true lack of potential drivers of change for sediment at these sites. Also, sample preparation procedures (Gray et al., 2000) that cause TSS trends to better capture changes in smaller sediment sizes (i.e., silts and clays) as opposed to larger sand-sized sediment may hinder the ability of TSS to capture the effects of conservation practices in a watershed. Several studies have shown that conservation practices lead to the preferential settling of coarser material as streamflow slows. For example, White et al. (2007) showed that forested filter strips are efficient at removing coarsetextured sediment but that small particles (generally clay and smaller) are not affected. Lee et al. (2000) found that trapping efficiencies varied depending on the vegetation type used in vegetative buffers but were highest for coarse sediment. Meyer et al. (1995) found that grass hedges trapped nearly all sand-sized sediment but allowed silt- and clay-sized sediment through. Bombino et al. (2008) found decreases in sediment size over a reach that had three check dams. Therefore, land management changes aimed at slowing streamflow to control sediment may show less of an effect when TSS (as opposed to SSC) is used to characterize sediment changes in a stream and may be one reason for the weak correlations shown in Fig. 4.

Typically, process-based watershed models (such as the Soil \& Water Assessment Tool; SWAT) are used to assess the effectiveness of conservation practices on water quality because identifying these effects empirically has proven challenging. Some work has been done to empirically relate CRP to changes in nutrients on a national scale (Sprague and Gronberg, 2012), but none specifically address sediment. Studies on the effects of CRP enrollment in individual watersheds give mixed results. Lizotte et al. (2012) found decreases in sediment in an oxbow lake related to the implementation of BMPs and CRP enrollment in the surrounding drainages. Cullum et al. (2010) found that conversion of cropped land into forested CRP land in the drainage surrounding an oxbow lake reduced the sediment load entering the lake by an order of magnitude. However, Davie and Lant (1994) found that CRP enrollment influenced sediment erosions rates but not sediment loads downstream. They suggest that the location of CRP near the stream may be important for affecting downstream sediment load. In support of this idea, the percent change in CRP enrollment in proximalzone agricultural land was well correlated with SSC trends 

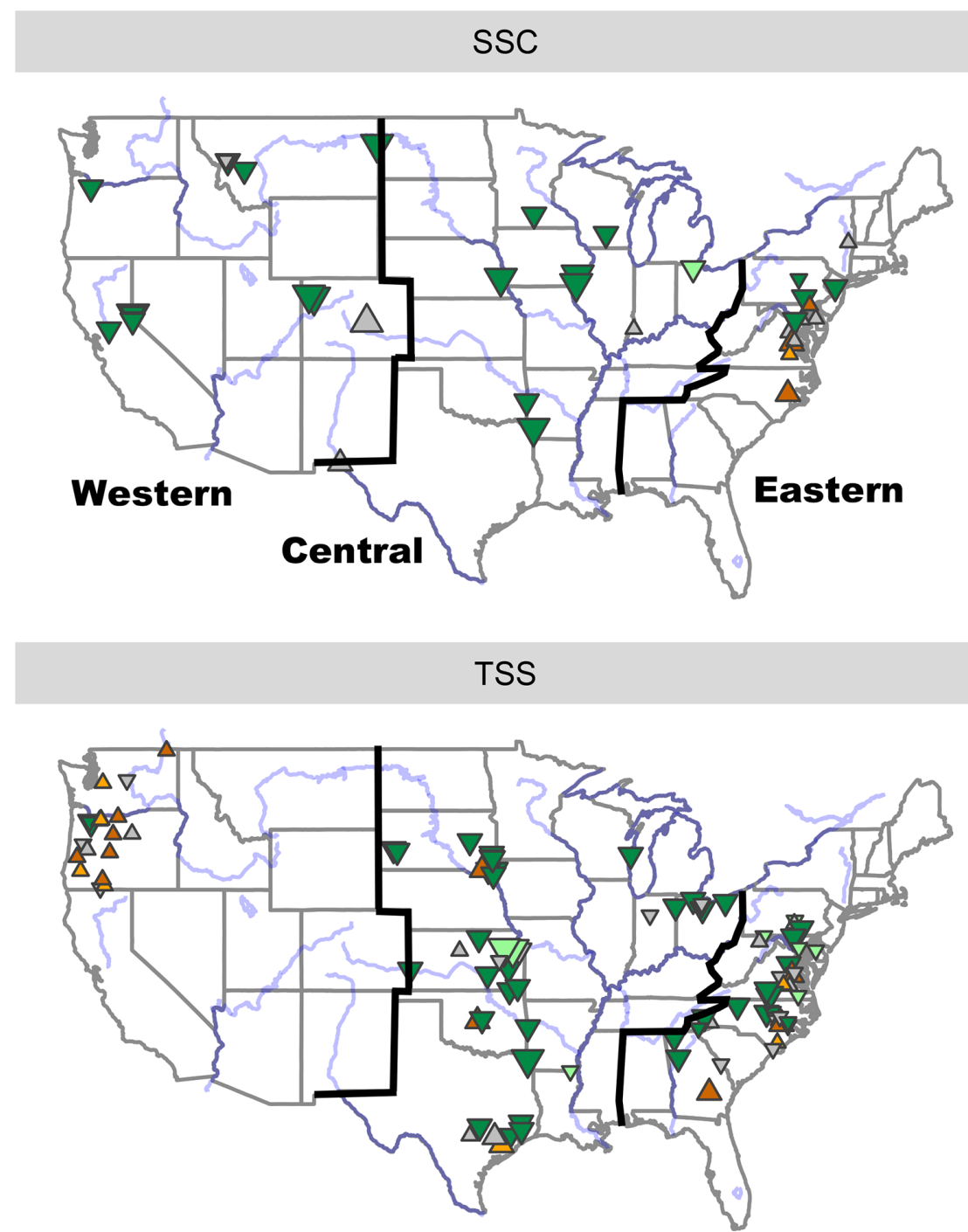

Magnitude of percent change

$>50 \%$ change

$5 \%-50 \%$ change

$<5 \%$ change

\section{Likelihood and} trend direction

$\triangle$ Likely upward (LU)

$\triangle$ Somewhat LU

$\triangle$ As LU as not

$\nabla$ As LD as not

$\nabla$ Somewhat LD

$\nabla$ Likely downward (LD)

Figure 1. Sediment trends from 1992 to 2012, showing trend direction, likelihood category and magnitude for suspended-sediment concentration (SSC) and total suspended-solid concentration (TSS). Base map generated using the ggmap package of the R statistical software program. (Kahle and Wickham, 2013).

at agricultural and undeveloped sites, albeit in a counterintuitive direction (Fig. 4). This relationship is largely driven by a handful of sites with decreases in SSC and CRP (Fig. 5a) and gives limited insight. A more likely reflection of the effects of CRP on sediment in streams is captured by the weak and slightly negative correlations between the CRP variables and TSS trends (Fig. 4). Figure 5b shows that increases in CRP are typically associated with decreases in TSS. This relationship provides evidence, though limited, that increases in CRP land in the proximal zone may lead to decreases in sediment concentration in nearby streams. The two undeveloped sites with substantial increases in TSS and large percent increases in CRP (Fig. 5b) are located in the northwestern US and have some of the lowest sediment concentrations in the dataset (e.g., between 3-7 $\mathrm{mg} \mathrm{L}^{-1}$ in 1992) and increased by only 2 or $3 \mathrm{mg} \mathrm{L}^{-1}$. Decreases in sediment concentration also appear to be related to how much land in the watershed was enrolled in CRP at the beginning of the trend period. When more than $2 \%$ of a watershed was enrolled in CRP in 1992, sediment almost always decreased by 2012 (Fig. 5c and d), which suggests several potential causes including long lag times between vegetation/soil health improvements and water-quality recovery, that 1992 CRP enrollment represented a commitment to better farming practices by the land owner, or that enrollment in CRP across the watershed needs to be above a certain threshold for effects of these changes to be seen as changes in riverine sediment transport.

Some of the strongest correlations occurred between sediment trends and changes in urbanization land use/cover variables at urban sites (Fig. 4). Construction related to urbaniza- 

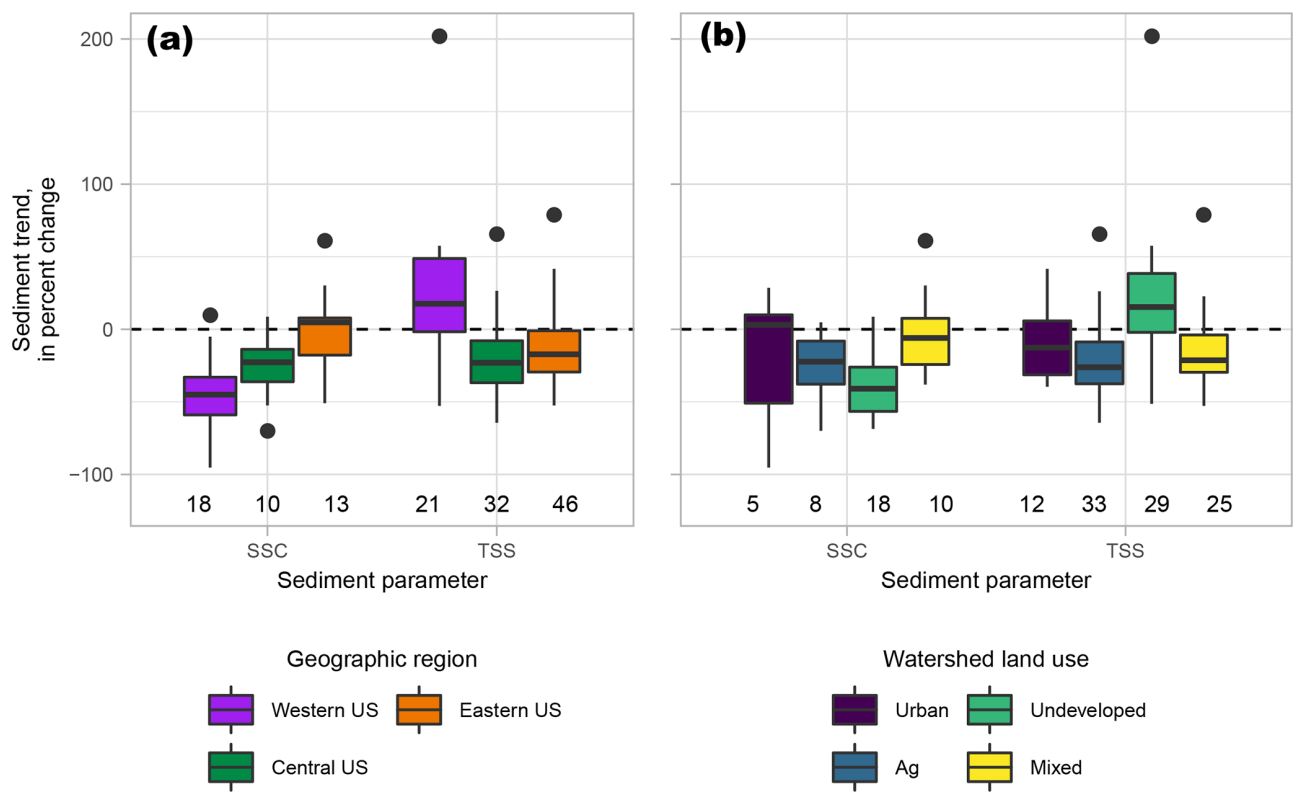

Figure 2. SSC and TSS trends by (a) geographic regions (depicted in Fig. 1) and (b) land use of watershed, including all sites and likelihoods. Dashed line denotes $0 \%$ change. Numbers above $x$ axis are site counts. For the boxplots, the top and bottom of the boxes correspond to the interquartile range (25th and 75th percentiles); top and bottom whiskers correspond to $1.5 \times$ (interquartile range); and points are data falling beyond $1.5 \times$ (interquartile range).

Table 3. Percent and number of sites with SSC and TSS trends for various combinations of QTC (sediment changes due to changes in the streamflow regime) and MTC (sediment changes due to changes in land management). Recall the sediment trend is equal to MTC + QTC "abs" refers to absolute.

\begin{tabular}{lcc}
\hline & SSC sites & TSS sites \\
\hline $\begin{array}{l}\text { MTC }>0 \\
\text { Changes in land management lead to increases in sediment }\end{array}$ & $20 \%(8)$ & $40 \%(40)$ \\
\hline $\begin{array}{l}\text { QTC }>0 \\
\text { Changes in the streamflow regime lead to increases in sediment }\end{array}$ & $41 \%(17)$ & $30 \%(30)$ \\
\hline $\begin{array}{l}\text { abs(QTC) } \geq \text { abs(MTC) } \\
\text { Changes in the streamflow regime contribute more to the sediment } \\
\text { (abs) trend than changes in land management }\end{array}$ & $17 \%(7)$ & $17 \%(17)$ \\
\hline $\begin{array}{l}\text { abs(QTC) } \geq 5 \% \\
\text { Changes in the streamflow regime contribute a non-negligible } \\
\text { amount of change to the sediment trend }\end{array}$ & $66 \%(27)$ & $57 \%(56)$ \\
\hline $\begin{array}{l}\text { abs(QTC }- \text { sediment trend) } \leq 10 \% \\
\text { Changes in the streamflow regime account for almost the entire } \\
\text { amount of change in sediment }\end{array}$ & $10 \%(4)$ & $20 \%(20)$ \\
\hline $\begin{array}{l}\text { And if, abs(sediment trend) } \geq \pm 5 \% \\
\text { In addition to abs(QTC }- \text { sediment trend) } \leq 10 \%, \text { the sediment } \\
\text { trend shows a non-negligible amount of change over the same } \\
\text { period }\end{array}$ & $2 \%(1)$ & $10 \%(10)$ \\
\hline $\begin{array}{l}\text { MTC and QTC have different signs } \\
\text { The effects of changes in streamflow regime and changes in land } \\
\text { management on sediment oppose each other leading to smaller } \\
\text { changes in sediment than either trend component alone }\end{array}$ & $51 \%(21)$ & $59 \%(58)$ \\
\hline
\end{tabular}



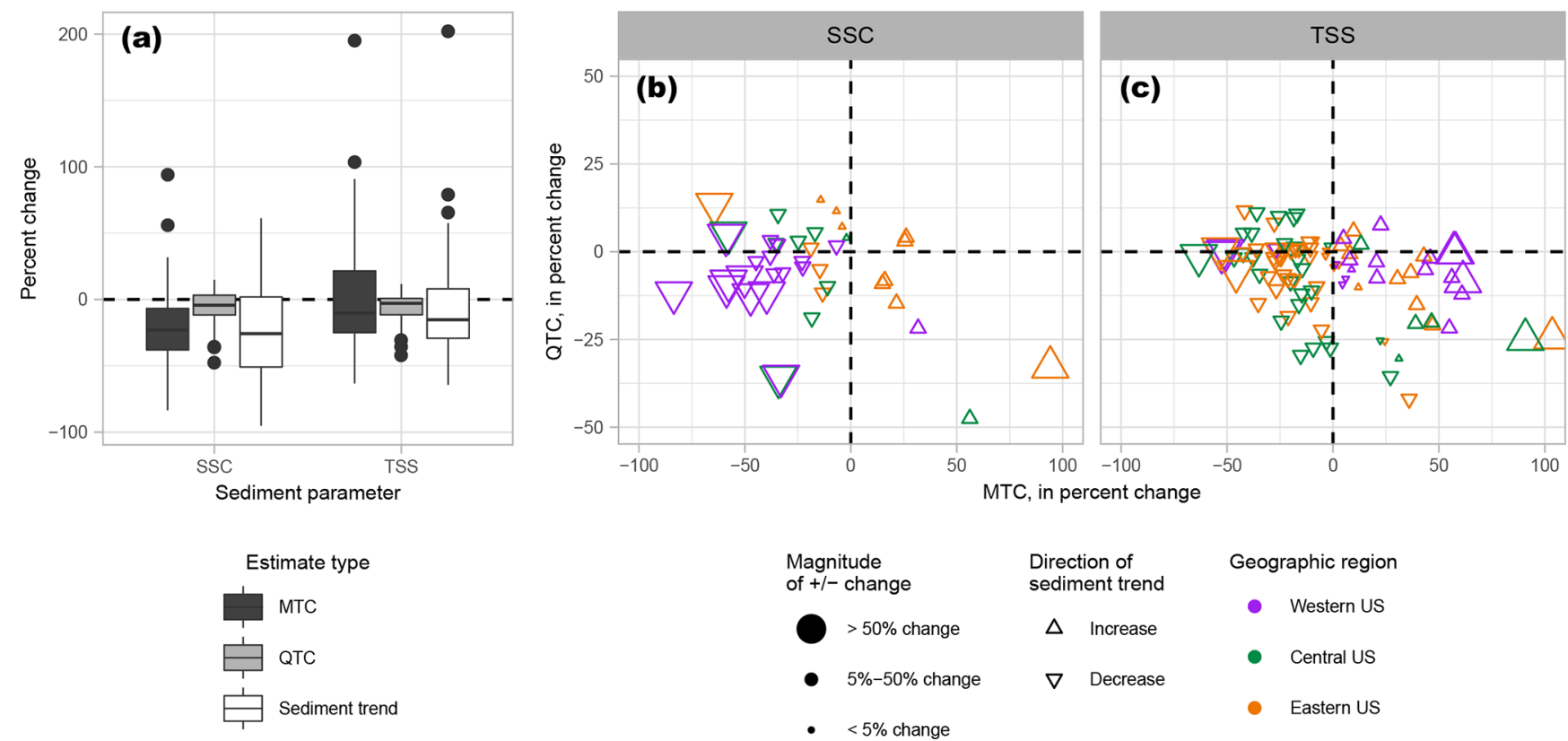

Figure 3. (a) Boxplots of sediment trend, management trend component (MTC) and streamflow trend component (QTC) estimates by sediment parameter. See description of boxplots in the caption of Fig. 2. (b, c) Bivariate plots of QTC versus MTC for each site by sediment parameter, color coded by geographic region and sized by the magnitude of sediment trend. Note that panels (b) and (c) exclude one undeveloped western US site (BRSS0035) with $195 \%$ MTC, $7 \%$ QTC and $202 \%$ sediment trend. Recall, at a given site, the sediment trend is equal to $\mathrm{MTC}+\mathrm{QTC}$.

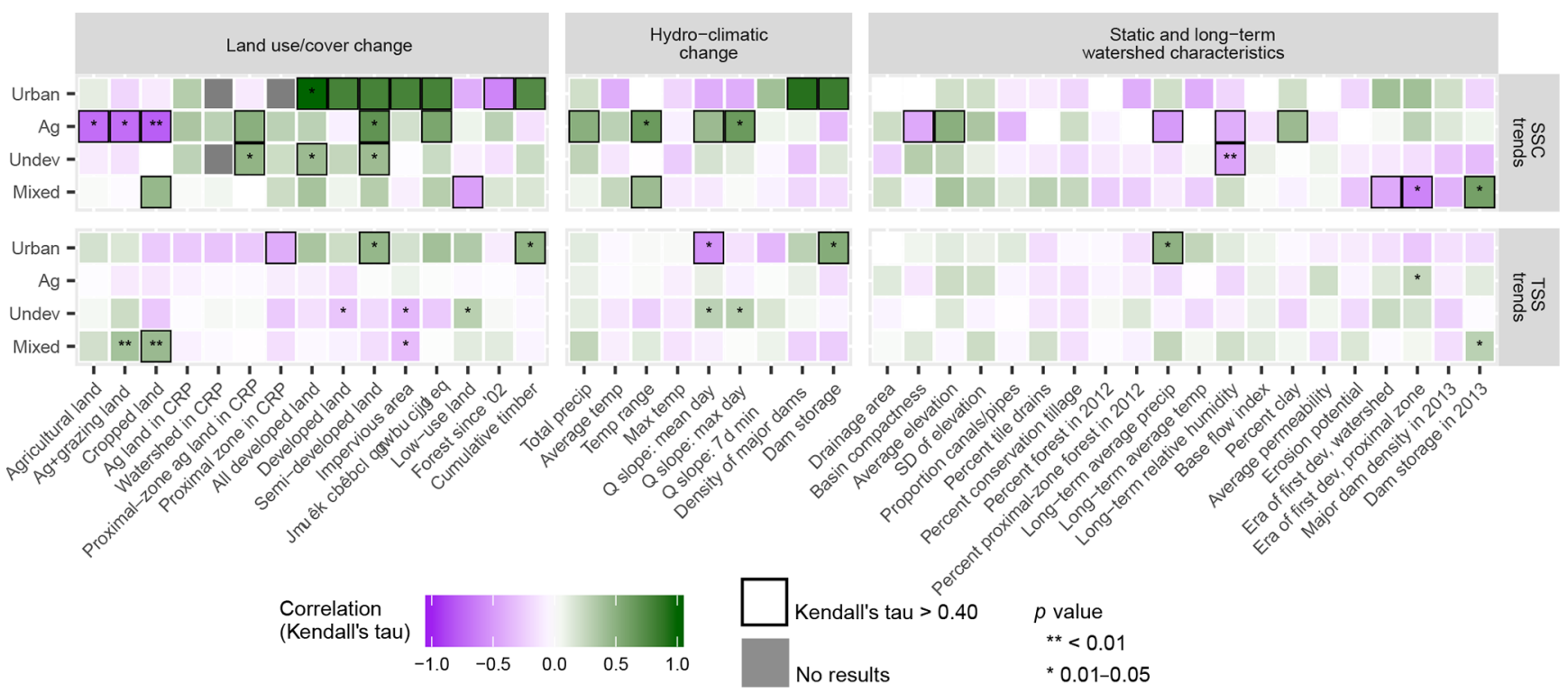

Figure 4. Correlations between 1992-2012 sediment trends and various potential drivers of change (land use/cover and hydro-climatic variables) and static/long-term watershed characteristics, grouped by the 2012 land use of the contributing watershed. Note that land use/cover change variables and hydro-climatic-change variables are correlated with sediment trends in percent change, whereas the static/long-term watershed characteristics were correlated with the sediment trends in absolute percent change. 

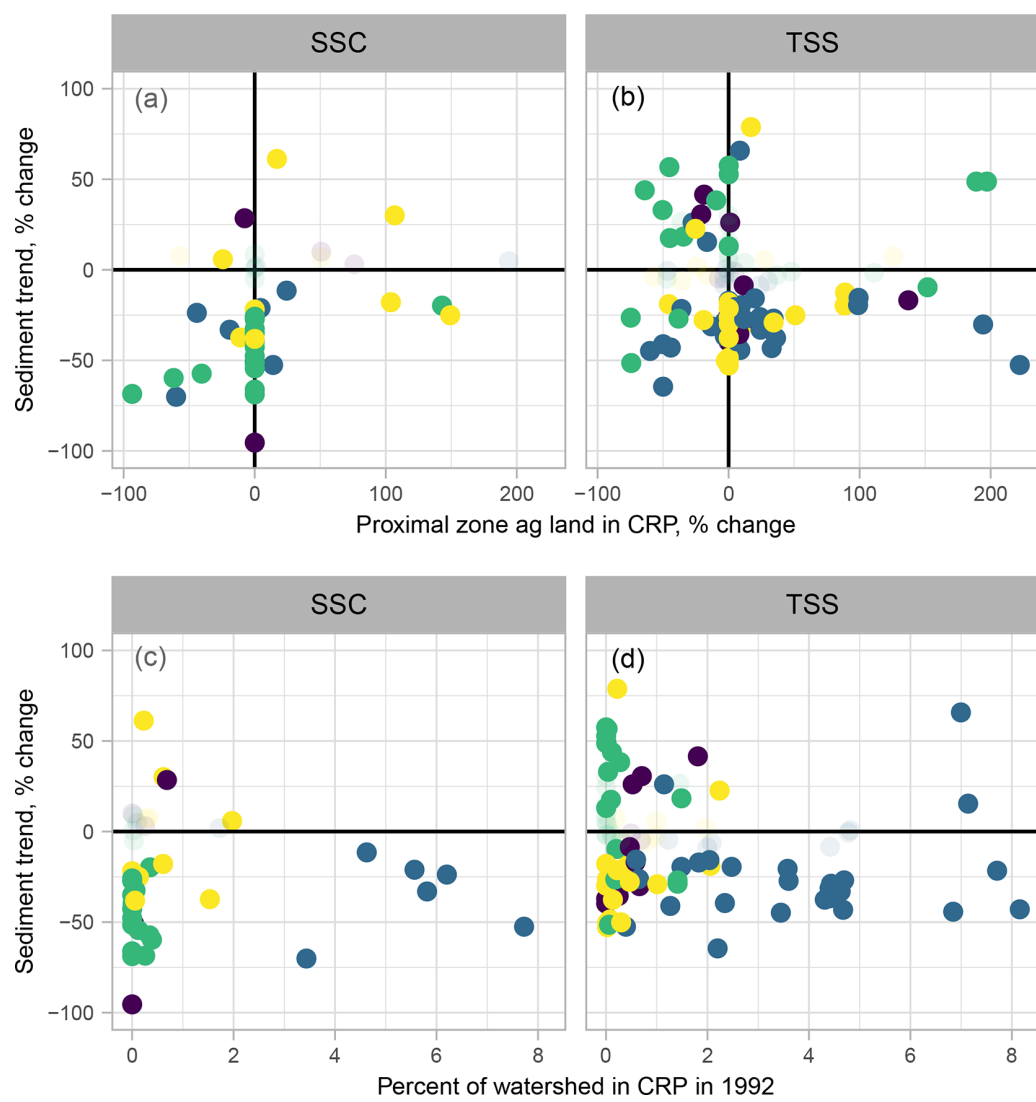

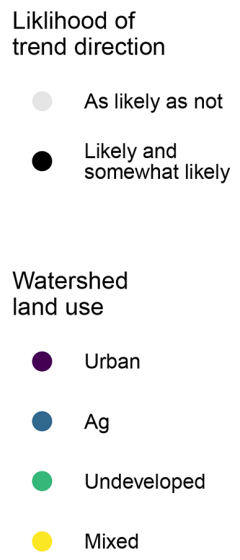

Watershed land use

Figure 5. (a, b) Sediment trend versus percent change in proportion of agricultural land in the proximal zone enrolled in the Conservation Reserve Program (CRP) between 1992 and 2012. (c, d) Sediment trend versus percent of land in watershed enrolled in the CRP during the trend start year (1992). Note that all plots exclude site BRSS0035 (202\% increase in TSS and $0 \%$ change in CRP).

tion disrupts the landscape, increases erosion and often leads to degraded water quality as larger quantities of sediment are transported to the stream. For example, increases in lowmedium-density dwellings likely indicate additional or new construction and earthmoving activities on previously lessdeveloped lands. MTC and the SSC trend both have a similar relationship to changes in low-medium-density dwellings (Fig. 6a and c), whereas QTC does not (Fig. 6e). The relationship between low-medium-density dwellings and QTC is more muted compared to MTC, indicating changes in lowmedium-density dwellings appear to affect overall sediment concentrations more strongly via changes in the $\mathrm{C}-\mathrm{Q}$ relationship compared to changes in the streamflow regime. Interestingly, despite continued urbanization and increases in some land uses often associated with worsening water quality, sediment concentration still largely decreased at urban sites (Fig. 2b). For example, increases in SSC only occurred at sites where low-medium-density dwellings increased by $30 \%$ or more (Fig. 6a). Conversely, small and moderate increases in low-medium-density dwellings occurred at sites with decreases or little change in SSC. Some of this success could be due to the implementation of BMPs at construction sites. BMPs aimed at preventing erosion and controlling eroded sediment, such as silt fencing, outlet protection, check dams, covering disturbed surfaces, diverting runoff and creating dewatering areas, may be successful, up to a point, at reducing sediment runoff to streams even as lands continue to be urbanized. This effect is less apparent for most undeveloped sites where there has been little change in low-mediumdensity dwellings (clustering of points around $x=0$ ) but still substantial decreases in SSC (Fig. 6a).

Sites with undeveloped or mixed-use watersheds provided limited insight on potential drivers of change, depending on the parameter. SSC trends at these sites were positively related to several land use/cover changes known to result in disturbed land, such as increases in cropped land, all developed land and semi-developed land (Fig. 4). Yet, as a group, undeveloped sites had some of the largest and most consistent decreases in SSC (Fig. 2) despite correlations with landdisturbing land use/cover variables, a pattern also observed for SSC sites with urban and agricultural watersheds. However, the SSC changes at mixed-used sites are less consistent and potential drivers of change are less clear. The cluster of increasing TSS concentrations in the northwestern US is notable compared to TSS trends in other geographic regions (Fig. 1), and these sites also tend to be undeveloped (Fig. S4). 


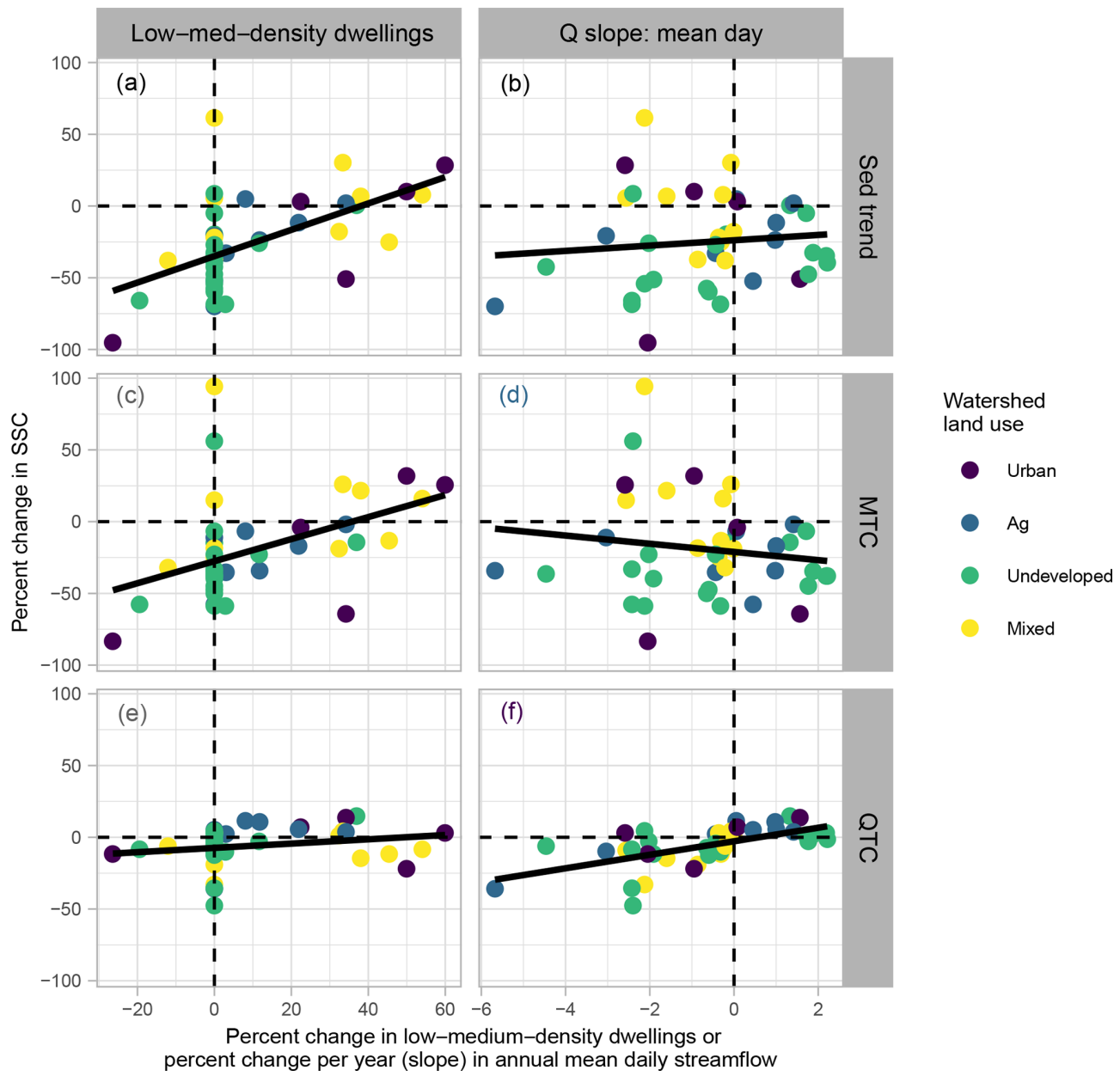

Figure 6. Bivariate plots of the SSC trend, MTC and QTC versus two potential causal variables: percent change in low-medium-density dwellings in the watershed and percent change per year (slope) of annual mean daily streamflow for the 1992-2012 trend period. Black line is an ordinary least-squares regression fit through all the data to show relationship between variables, and dashed lines indicate $0 \%$ change. Sed: sediment.

Conceptually, potential drivers of these sediment increases could be increases in developed land, increases in timber and decreases in forest cover. However, these variables were not well correlated with TSS trends at undeveloped or mixed-use sites (Fig. 4). This may partially be because temporally and spatially consistent data on forest cover and timber are only available beginning in 2001 and 1999, respectively (Table 1; Falcone, 2017).

\subsection{Hydro-climatic changes}

QTC provides a general estimate of the amount of change in sediment due exclusively to changes in the streamflow regime. When QTC is large, in absolute terms, natural or human activities could be causing these changes. For example, systematic changes in climate due to increased greenhouse gases in the atmosphere, quasi-periodic fluctuations in climate (such as the El Niño-Southern Oscillation), changes in dam operations or extensive alteration of the stream chan- nel (e.g., straightening or channelization) could all induce a change in streamflow over time, which in turn could lead to changes in the transport, resuspension and erosion of sediment within the channel, riparian zone and floodplain. Using a slightly longer trend period, Murphy and Sprague (2019) found sediment trends, compared to other water-quality parameters, were more likely to be comprised of contributions of both MTC and QTC - meaning changes in both management and the streamflow regime often contributed to changes in riverine sediment. Similarly, this study finds that around $60 \%$ of the sites had non-negligible QTC contributions ( $> \pm 5 \%$ change) to sediment trends (Table 3 ). These contributions tend to be much smaller than MTCs (Fig. 3a), and only about $17 \%$ of the sites had a QTC that exceeded MTC (Table 3). At a limited number of sites, changes in streamflow accounted for almost the entire change in sediment (10\% of SSC sites and $20 \%$ of TSS sites; Table 3), though many of these sediment trends were small. Only 1 of 
the SSC trends and 10 of the TSS trends had both an increase (or decrease) of at least $5 \%$ that was almost entirely due to changes in the streamflow regime with little-to-no contributions from changes in land management. Thus, while changes in the streamflow regime were typically not the dominant driver of changes in sediment concentration, they were often a contributing factor, and at a few sites they were the main driver of change.

The correlative strength of hydro-climatic changes with sediment trends across land use categories and parameters was not uniform (Fig. 4). At undeveloped sites, none of the hydro-climatic variables were well correlated with SSC trends and only 2 streamflow trend variables had significant but low-magnitude correlations, suggesting that climate change and climate variability alone were not sufficiently strong to affect sediment concentrations across these sites. There is limited consensus on how changes in climate thus far have influenced sediment in rivers (see references in Whitehead et al., 2009 and Wohl, 2015). However, human influences, especially dam construction and management, have been shown to be important drivers of change in other areas (Walling, 2009; Rossi et al., 2009; Williams and Wolman, 1984). Surprisingly, the results in this study suggest a limited influence from dams on sediment trends. Changes in the storage capacity of major dams and changes in the number of dams in the watershed were only well correlated with sediment trends at urban sites (Fig. 4) - only two sites showed a change in either variable, both of which had small $(\sim 7 \%)$ or moderate $(\sim 25 \%)$ increases in sediment. However, neither site was close to a dam (both $>5 \mathrm{~km}$ downstream of a dam), and these increases in the number of dams and dam storage may be occurring much farther upstream from the site. In fact, only 7 and 10 sites with SSC and TSS data, respectively, were within $5 \mathrm{~km}$ downstream of a dam. Also, the direction of the sediment trends at these handful of sites were mixed, and across all sites the number of dams and dam storage volume only increased between 1992 and 2012 (i.e., no site in this dataset had a decrease in the number of dams or amount of storage in the watershed). Thus, the limited effect of dams on sediment trends that was observed in this study is likely because the characteristics of this dataset and the included sites are not optimal for exploring the effect of dams in detail. Additional work explicitly considering sites closer to dams and information such as dam proximity, the proportion of total streamflow controlled by dams and trapping efficiency of upstream dams would further illuminate this potential driver of change.

Variables characterizing trends in specific annual metrics of daily streamflow ("Q slope: mean day", "Q slope: $\max$ day" and "Q slope: $7 \mathrm{~d}$ min") had a few moderate correlations with sediment trends (Fig. 4). However, QTC estimates indicate stronger influences from changes in the streamflow regime (Table 3) than is apparent from the correlations with the sediment trend (Fig. 7). When the correlation analysis was repeated using QTC instead of the sedi- ment trend, often one or two of the streamflow trend variables are well correlated with QTC in each of the land use categories (Fig. 7d), indicating that changes in the streamflow regime are influencing sediment concentrations, but these changes are largely being masked by changes in concentration due to land management (MTC). This effect was also seen for other water-quality parameters in Murphy and Sprague (2019). Figure 6 demonstrates this effect by comparing bivariate plots of the sediment trend, MTC and QTC to a land use change variable and hydro-climatic-change variable. The sediment trend is not well correlated with a change in annual mean daily streamflow (Fig. 6b). However, the welldefined positive relationship between mean daily streamflow and QTC indicates that increases or decreases in streamflow relate to corresponding increases or decreases in sediment concentration (Fig. 6f). This pattern is quite different from when the percent change in low-medium-density dwellings is compared to the sediment trend, MTC and QTC (Fig. 6a, c and e). These relationships suggest that decreases in streamflow also decrease sediment transport or resuspension in the stream, but these improvements may be partially offset by human activities in a given watershed, such as increases in low-medium-density dwellings. Thus, the low correlations between streamflow change variables and sediment trends shown in Fig. 4 may be downplaying the importance of changes in the streamflow regime on sediment trends.

An additional consideration is that changes in streamflow can also induce a change in the $\mathrm{C}-\mathrm{Q}$ relationship, and this response may be more common for sediment compared to other water-quality parameters. Recall that MTC captures the influence of changes in the $\mathrm{C}-\mathrm{Q}$ relationship on sediment concentration; thus if the streamflow regime changed in such a way to perturb the $\mathrm{C}-\mathrm{Q}$ relationship, this effect would be captured by MTC. C-Q relationships have been shown to vary by storm depending on a host of hydrologic and antecedent conditions and over short time periods due to droughts or highly wet years (Duncan et al., 2017; Biron et al., 1999). However, sustained, systematic changes in the $\mathrm{C}-\mathrm{Q}$ relationship due exclusively to changes in the streamflow regime are less well documented (e.g., Bieroza et al., 2018). A few of the hydro-climatic-change variables were well correlated with MTC, though again, primarily at urban and agricultural sites (Fig. 7b). This finding suggests a limited ability of hydro-climatic changes to systematically shift the $\mathrm{C}-\mathrm{Q}$ relationship over time, at least for sediment concentrations at these sites. QTC was much more strongly correlated with hydro-climatic-change variables (Fig. 7d), compared to land use/cover variables (Fig. 7c), across all land use categories and for both sediment-sample types, showing the importance of changes in streamflow on sediment, even if these changes are often masked or counteracted. Understanding the sensitivity of the $\mathrm{C}-\mathrm{Q}$ relationship (i.e., MTC) to systematic changes in the streamflow regime would further illuminate the effects of such changes on sediment concentration in rivers and streams. 


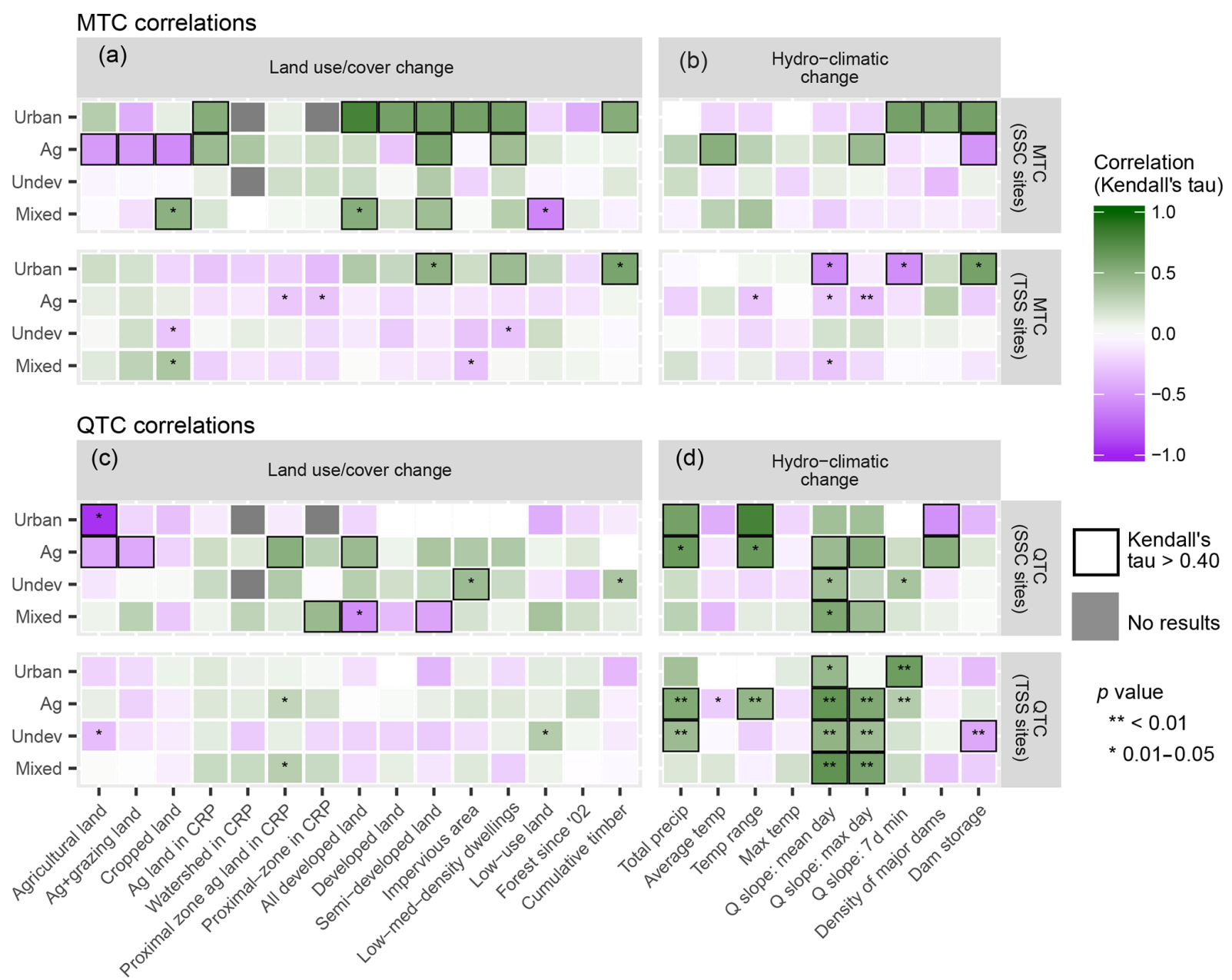

Figure 7. Correlations between MTC or QTC and land use/cover or hydro-climatic-change variables by sediment parameter. Sites grouped by 2012 land use of contributing watershed.

\subsection{Importance of location}

Sediment dynamics are strongly influenced by geographic location and are particularly sensitive not only to the land use of the watershed, floodplain and riparian zone but also to the geologic, climatologic, physiologic and geomorphologic conditions of the site (Charlton, 2007). The location of a sampled site in a fluvial system's longitudinal profile can be an important factor in the types and amounts of sediment available for transport, particularly if that stretch of river is supply-limited or transport-limited. Similarly, channel evolution processes are an important determinant of sediment dynamics. For example, if a site is located on or downstream of a length of river that shifts from an aggradation to degradation phase, this would change sediment concentrations over time. Gellis et al. (1991) found that decreases in sediment and salt loads in the Colorado River basin were likely due to a natural shift in incised-channel evolution, which includes sequential phases involving channel deepening and widening and then the deposition of a floodplain. Changes in sed- iment loads related to this natural geomorphic process were further exacerbated by concurrent changes in the streamflow regime (Gellis et al., 1991). These natural factors can influence not only a site's capacity for change but also its recovery potential (Charlton, 2007). Multiple static and longterm watershed conditions (Table 1) were used to explore the sensitivity of sediment trends to location. Surprisingly, only a few of the land use categories had sediment trends that were well correlated with one or more of the 20 static/longterm watershed characteristics, this was again more so for SSC trends than TSS trends (Fig. 4). Since the sediment trends were in terms of absolute change for these correlations, positive (negative) correlations indicate increased (decreased) sensitivity of sediment concentrations at a site as the gradient of a given static/long-term watershed characteristic increases, leading to larger (smaller) sediment trends. For example, SSC trends at undeveloped sites were negatively correlated with long-term relative humidity, indicating that smaller changes in sediment (increases or decreases) occurred at sites with higher relative humidity. Sites with high 
relative humidity tend to also be more vegetated, and the amount of sediment readily available for transport at these sites is less than at a more arid site. Thus, SSC at more arid sites is more sensitive to hydrologic or land management changes than at humid sites.

MTC and QTC estimates suggest location is important for understanding the potential drivers of change in sediment concentration. When grouped broadly by geographic region, western US sites, which also are often undeveloped (Fig. S4), typically have negative QTCs for both SSC and TSS trends, indicating changes in streamflow tend to lead to potential decreases in sediment in this region (Fig. 3b and c). However, changes in overall sediment are quite different for SSC and TSS trends at these sites (Fig. 1). Decreasing SSC trends at western sites typically have negative QTCs coupled with larger but also negative MTCs, suggesting changes in the streamflow regime further enhanced larger decreases in sediment from changes in land management (Fig. 3b). The opposite is seen for increasing TSS trends at western sites; negative QTCs are coupled with larger positive MTCs. Thus, even though changes in the streamflow regime partially offset potential increases in sediment due to changes in land management, the overall sediment concentration still increased (Figs. 3c, 1). This opposing effect results in somewhat smaller sediment trends than would have been observed if the streamflow regime had remained stationary over this period. An example of opposing MTC and QTC at a single site is given in Murphy and Sprague (2019). In that example, SSC in the Skunk River (Iowa, US) had a value of $-90 \%$ MTC and $20 \%$ QTC, giving an overall decrease of $-70 \%$ in sediment concentration. The negative MTC was attributed to transitioning erodible land out of production, which likely decreased the amount of available sediment for transport. The positive QTC was attributed to increases in spring and summer streamflow over this same period, which likely led to increased mobilization of sediment to the stream, partially offsetting the improvements shown by MTC. For western TSS sites, it appears changes in land management resulted in increases in sediment which were somewhat lower than expected due to concurrent changes in the streamflow regime over the same time.

Central and eastern US sites show a mix of opposing and reinforcing effects of MTC and QTC on sediment trends (Fig. 3b and c). For both parameters, about half of the sites had opposing effects, and the other half had reinforcing effects on the sediment trend (Table 3; Fig. S5). However, it was relatively rare for both QTC and MTC to be positive, indicating it was uncommon for increases in sediment to be due to increases from both changes in land management and changes in streamflow. Instead, increases from changes in land management were more often slightly offset by decreases from changes in the streamflow regime (negative QTCs; Fig. 3b and c). Finally, QTC was near zero for about half of TSS trend sites (Table 3), largely at sites in the eastern US (Fig. 3c). Since TSS trends tend to not capture changes in coarser suspended sediment (as compared to SSC), it may be that TSS trends are less sensitive to changes in the streamflow regime, particularly when these changes occur at higher streamflow, which has been observed in many rivers in the eastern US (e.g., Armstrong et al., 2014).

\subsection{Limitations and outlook}

In many ways, the datasets used here provide a greater breadth and depth of information for exploring potential causes of sediment trends compared to previous studies: the datasets are temporally consistent and thus comparable over time, spatially consistent and thus allow for comparison across sites, publicly available with well-documented metadata, and spatially explicit and thus allow for estimates of the watershed and the proximal zone (Falcone, 2017). However, even with this extensive information, it was difficult to identify specific potential drivers of sediment trends for some land use categories. Additionally, because multiple correlations were completed (176 for each set of SSC and TSS trends shown in Fig. 4), about two and nine of the statistically significant correlations at the alpha 0.01 and 0.05 level, respectively, can be expected to be false positives.

The difficulty of establishing clear, straightforward relationships between potential drivers of change and sediment trends presents a real challenge for researchers, especially those working with streams across a large geographic region. It is possible that the choice of potential causal variables used in these analyses did not capture the relevant changes at these sites. Other variables, if available, may better characterize important changes on the landscape or in land management. There is quite possibly a disconnect between the conceptual land management changes identified while parsing the sediment trends and the land use/cover change information that was available for the correlation analysis. Information that could be helpful but often is not available in a nationally or temporally consistent dataset include channel and floodplain geomorphological characteristics, construction activities near the site, types and density of riparian vegetation, BMP information, changes in dam operations, and details about whether the site is undergoing channel evolution and whether the site is in an degradation or aggradation phase.

The use of TSS to characterize changes in sediment may make exploring potential causes more difficult than when SSC is used. As described in Sect. 2.1, TSS tends to measure the concentration of smaller suspended particle sizes as opposed to the entire suspended particle-size distribution of a sample and has been "shown to be fundamentally unreliable for the analysis of natural-water samples" (Gray, et al., 2000). The uncertainty inherent in TSS estimates is a likely explanation for the low correlations between TSS trends and potential causal variables (Fig. 4). However, heterogeneity across the sites and difficulty in identifying potential causes of change in only the fine suspended-sediment fraction (less sands) are other possibilities. TSS and SSC trends can also 
give quite different results. In Murphy et al. (2018), five sites with 2002-2012 trends and three sites with 1992-2012 trends had both types of sediment data. These trends had different magnitudes, and a few had different trend directions depending on the sediment parameter (Fig. S6), which supports the conclusion of the incompatibility of SSC and TSS estimates as shown by Gray et al. (2000). Thus, caution should be taken when comparing TSS and SSC results, and researchers should note the possible difficulties when using TSS estimates to understand changes in sediment and their potential drivers.

Additionally, sediment may present a relatively unique challenge when trying to identify potential drivers of trends compared to other water-quality parameters, such as pesticides or nutrients. Sediment transport is fundamentally different from other water-quality parameters, relying on the physical properties of fluid dynamics as opposed to chemical reactions. For example, stream bank erosion can be a dominant contributor of suspended material to a river, and while adjacent land use/cover and management can be important in determining the amount of erosion (Fox et al., 2016), it is also possible that channel erosion is more strongly related to channel properties and conditions, such as channel roughness, slope, sinuosity, and near-channel vegetation density and type (Charlton, 2007). Changes in these variables are difficult to track over time, and a unified dataset containing such information for multiple sites across a specific geographic region or the US is non-existent. Also, the source and mobilization of sediment can be natural or human-influenced and includes the remobilization of legacy sediment (Wohl, 2015). Changes in land management may have led to the deposition of sediment stores in the channel and floodplain, but a change in the streamflow regime may be the ultimate factor causing the erosion and transport of the stored sediment downstream.

The next directions for better understanding drivers of sediment trends include practical activities, such as continued high-quality sediment monitoring, the maintenance of current river monitoring networks, and the development and maintenance of datasets that describe likely drivers of change. This analysis identified some important gaps in available explanatory datasets like the lack of a long-term dataset that describes forest cover and timber across the US. Next directions also include conceptual developments focused on the use of improved methods for linking changes in river sediment with potential drivers of change and considering the interconnected ways changes in the streamflow regime influence $\mathrm{C}-\mathrm{Q}$ relationships. This will include drawing on techniques from other scientific fields, such as epidemiology, that also collect and analyze longitudinal observational data. Finally, though many of the 137 sites across the US saw decreases in sediment, this analysis also showed that sediment concentration readily responds to changes in streamflow. Thus, decreases in sediment from conservation practices and BMPs will need to be commensurate with pro- jected changes in climate and its subsequent effects on the hydrologic cycle.

\section{Conclusion}

Annual mean concentrations of suspended sediment largely decreased between 1992 and 2012 at 137 stream sites with watershed areas $<300000 \mathrm{~km}^{2}$ across the contiguous US. Many of these decreases occurred at sites with some of the highest concentrations and at sites that drained watersheds with concurrent small-to-moderate increases in human-related land uses (i.e., urban and agricultural land uses), suggesting efforts to minimize sediment pollution to streams and rivers may be having the desired effect in some places. A notable exception to these decreases is a cluster of increasing TSS concentrations at undeveloped sites in the northwestern US. At $83 \%$ of sites, a change in land management (including changes in land use/cover), as opposed to a change in the streamflow regime, was the primary contributor of changes in sediment, though systematic changes in the streamflow regime had a mild-to-moderate influence on sediment at $66 \%$ of SSC sites and $57 \%$ of TSS sites (Table 3). Across all sites, the median MTC was $-23 \%$ and $-10 \%$ for SSC and TSS trends, respectively, compared to the median QTC of $-4 \%$ (SSC) and $-3 \%$ (TSS) (Fig. 3). The influence of specific hydro-climatic changes on sediment trends appears to be masked due to more influential changes in land management. Sediment trends determined using TSS data were weakly correlated with potential causal variables, highlighting the difficultly of using TSS, as opposed to SSC, to infer potential causal relationships largely due to not only the unreliability of TSS for characterizing stream water quality but also differences in suspended particle-size distributions. While identifying the specific land use/cover or hydroclimate changes responsible for these sediment decreases remains a challenge, the strongest correlations tended to occur at sites with more homogenous, human-related land uses (i.e., agricultural and urban lands). At many sites, across all land use categories, decreases in sediment are likely due to changes in land management with changes in the streamflow regime providing a limited though important and often overlooked influence.

Data availability. Site information and the sediment concentration and streamflow data used to estimate the trends are published at: https://doi.org/10.5066/F7KW5D4H (De Cicco et al., 2017); the land use data are available at: https://doi.org/10.5066/F7TX3CKP (Falcone, 2017); the streamflow trend data are available at: https://doi.org/10.5066/F7D798JN (Farmer et al., 2017); and the estimates of the sediment trends, management trend components (MTC) and streamflow trend components (QTC) are available at https://doi.org/10.5066/F7TQ5ZS3 (Murphy et al., 2018). 
Supplement. The supplement related to this article is available online at: https://doi.org/10.5194/hess-24-991-2020-supplement.

Competing interests. The author declares that there is no conflict of interest.

Disclaimer. Any use of trade, firm, or product names is for descriptive purposes only and does not imply endorsement by the U.S. Government.

Acknowledgements. This work would not have been possible without the nationwide trends assessment completed by the USGS National Water Quality Assessment Project's Surface Water Status and Trends team, including Lori Sprague, Gretchen Oelsner, Henry Johnson, Edward Stets, Melissa Riskin, Karen Ryberg and James Falcone.

Financial support. This research has been supported by the National Water Quality Assessment Project.

Review statement. This paper was edited by Christian Stamm and reviewed by two anonymous referees.

\section{References}

American Public Health Association, American Water Works Association, and Water Pollution Control Federation: Standard methods for the examination of water and wastewater, 19th edn., American Public Health Association, Washington, D.C., USA, 1995.

American Society for Testing and Materials (ASTM): Standard test methods for determining sediment concentration in water samples, D 3977-97, vol. 11.02, Water (II), 395-400, 2000.

Armstrong, W. H., Collins, M. J., and Synder, N. P.: Hydroclimatic flood trends in the northeastern United States and linkages with large-scale atmospheric circulation patterns, Hydrolog. Sci. J., 59, 1636-1655, 2014.

Basu, N. B., Destouni, G., Jawitz, J. W., Thompson, S. E., Loukinova, N. V., Darracq, A., Zanardo, S., Yaeger, M., Sivapalan, M., Rinaldo, A., Suresh, P., and Rao, C.: Nutrient loads exported from managed catchments reveal emergent biogeochemical stationarity, Geophys. Res. Lett., 37, L23404, https://doi.org/10.1029/2010GL045168, 2010.

Bieroza, M. Z., Heathwaite, A. L., Bechmann, M., Kyllmar, K., and Jordan, P.: The concentration-discharge slope as a tool for water quality management, Sci. Total Environ., 630, 738-749, 2018.

Biron, P. M., Roy, A. G., Courschesne, F., Hendershot, W. H., Cote, B., and Fyles, J.: The effects of antecedent moisture conditions on the relationship of hydrology to hydrochemistry in a small forested watershed, Hydrol. Process., 13, 1541-1555, 1999.
Bombino, G., Gurnell, A. M., Tamburino, V., Zema, D. A., and Zimbone, S. M.: Sediment size variation in torrents with check dams: Effects on riparian vegetation, Ecol. Eng., 32, 166-177, 2008.

Brown, T. C. and Froemke, P.: Nationwide Assessment of Nonpoint Source Treats to Water Quality, BioScience, 62, 136-146, 2012.

Carey, R. O., Migliaccio, K. W., Li, Y., Schaffer, B., Kiker, G. A., and Brown, M. T.: Land use disturbance indicators and water quality variability in the Biscayne Bay Watershed, Florida, Ecol. Indic., 11, 1093-1104, 2011.

Chanat, J. G. and Yang, G.: Exploring Drivers of Regional Water-Quality Change Using Differential Spatially Referenced Regression - A Pilot Study in the Chesapeake Bay Watershed, Water Resour. Res., 54, 8120-8145, https://doi.org/10.1029/2017WR022403, 2018.

Chanat, J. G., Moyer, D. L., Blomquist, J. D., Hyer, K. E., and Langland, M. J.: Application of a weighted regression model for reporting nutrient and sediment concentrations, fluxes, and trends in concentration and flux for the Chesapeake Bay Nontidal Water-Quality Monitoring Network, results through water year 2012, U.S. Geological Survey Scientific Investigations Report 2015-5133, 76 pp., https://doi.org/10.3133/sir20155133, 2016.

Charlton, R.: Fundamentals of Fluvial Geomorphology, Routledge, New York, USA, 280 pp., 2007.

Choquette, A. F., Hirsch, R. M., Murphy, J. C., Johnson, L. T., and Confesor Jr., R. B.: Tracking changes in nutrient delivery to western Lake Erie: Approaches to compensate for variability and trends in streamflow, J. Great Lakes Res., 45, 21-39, 2019.

Cullum, R. F., Locke, M. A., and Knight, S. S.: Effects of Conservation Reserve Program on Runoff and Lake Water Quality in an Oxbow Lake Watershed, Journal of International Environmental Application and Science, 5, 318-328, 2010.

Davie, D. K. and Lant, C. L.: The effect of CRP enrollment on sediment loads in two southern Illinois streams, J. Soil Water Conserv., 49, 407-412, 1994.

De Cicco, L. A., Sprague, L. A., Murphy, J. C., Riskin, M. L., Falcone, J. A., Stets, E. G., Oelsner, G. P., and Johnson, H. M.: Water-quality and streamflow datasets used in the Weighted Regressions on Time, Discharge, and Season (WRTDS) models to determine trends in the Nation's rivers and streams, 1972-2012, U.S. Geological Survey data release, https://doi.org/10.5066/F7KW5D4H, 2017.

Duncan, J. M., Welty, C., Kemper, J. T., Groffman, P. M., and Band, L. E.: Dynamics of nitrate concentration-discharge patterns in an urban watershed, Water Resour. Res., 53, 7349-7365, 2017.

Falcone, J. A.: U.S. conterminous wall-to-wall anthropogenic land use trends (NWALT), 1974-2012, US Geological Survey Data Series 948, https://doi.org/10.3133/ds948, 2015.

Falcone, J. A.: Watershed characteristics for study sites of the Surface Water Trends project, National Water Quality Program, U.S. Geological Survey data release, https://doi.org/10.5066/F7TX3CKP, 2017.

Farmer, W. H., Murphy, J. C., Riskin, M. L., Ryberg, K. R., and Zuellig, R. E.: Daily streamflow datasets used to analyze trends in streamflow at sites also analyzed for trends in water quality and ecological condition in the Nation's rivers and streams, U.S. Geological Survey data release, https://doi.org/10.5066/F7D798JN, 2017.

Ficklin, D. L., Stewart, I. T., and Maurer, E. P.: Effects of climate change on stream temperature, dissolved oxygen, and sediment 
concentration in the Sierra Nevada in California, Water Resour. Res., 49, 2765-2782, 2013.

Fox, G. A., Purvis, R. A., and Penn, C. J.: Streambanks: A net source of sediment and phosphorus to streams and rivers, J. Environ. Manage., 181, 602-614, 2016.

Gao, P., Geissen, V., Ritsema, C. J., Mu, X.-M., and Wang, F.: Impact of climate change and anthropogenic activities on stream flow and sediment discharge in the Wei River basin, China, Hydrol. Earth Syst. Sci., 17, 961-972, https://doi.org/10.5194/hess17-961-2013, 2013.

Gellis, A., Hereford, R., Schumm, S. A., and Hayes, B. R.: Channel evolution and hydrologic variations in the Colorado River basin: factors influencing sediment and salt loads, J. Hydrol., 124, $317-$ 344, 1991.

Gitau, M. W., Chaubey, I., Gbur, E., Pennington, J.H., and Gorham, B.: Impacts of land-use change and best management practice implementation in a Conservation Effects Assessment Project watershed: Northwest Arkansas, J. Soil Water Conserv., 65, 353 368,2010

Gray, J. R., Glysson, G. D., Turcios, L. M., and Schwarz, G. E.: Comparability of Suspended-Sediment Concentration and Total Suspended Solids Data. U.S. Geological Survey WaterResources Investigations Report 00-4191, Reston, Virginia, USA, 2000.

Hirsch, R. M., Moyer, D. L., and Archfield, S. A.: Weighted Regressions on Time, Discharge, and Season (WRTDS), with an Application to Chesapeake Bay River Inputs, J. Am. Water Resour. As., 46, 857-880, 2010.

Hirsch, R. M., Archfield, S. A., and De Cicco, L. A.: A bootstrap method for estimating uncertainty of water quality trends, Environ. Model. Softw., 73, 148-166, 2015.

Hirsch, R. M., De Cicco, L., Watkins, D., Carr, L., and Murphy, J.: EGRET: Exploration and Graphics for RivEr Trends, version 3.0, available at: https://CRAN.R-project.org/package=EGRET (last access: 27 February 2020), 2018a.

Hirsch, R. M., De Cicco, L., and Murphy, J.: EGRETci: Exploration and Graphics for RivEr Trends (EGRET) Confidence Intervals, version 2.0, available at: https://CRAN.R-project.org/package= EGRETci (last access: 27 February 2020), 2018b.

Irvine, K. M., Miller, S. W., Al-Chokhachy, R. K., Archer, E. K., Roper, B. B., and Kershner, J. L.: Empirical evaluation of the conceptual model underpinning a regional aquatic long-term monitoring program using causal modeling, Ecol. Indic., 50, 823, 2015.

Kahle, D. and Wickham, H.: ggmap: Spatial Visualization with ggplot2, R J., 5, 144-161, 2013.

Kendall, M. G.: A New Measure of Rank Correlation, Biometrika, 30, 81-93, 1938.

Kreiling, R. M. and Houser, J. N.: Long-term decreases in phosphorus and suspended solids, but not nitrogen, in six upper Mississippi River tributaries, 1992-2014, Environ. Monit. Assess., 188, 454, https://doi.org/10.1007/s10661-016-5464-3, 2016.

Lacher, I. L., Ahmadisharaf, E., Fergus, C., Akre, T., Mcshea, W. J., Benham, B. L., and Kline, K. S.: Scale-dependent impacts of urban and agricultural land use on nutrients, sediment, and runoff, Sci. Total Environ., 652, 611-622, 2019.

Lee, C. J., Hirsch, R. M., Schwarz, G. E., Holtschlag, D. J., Preston, S. D., Crawford, C. G., and Vecchia, A. V.: An evaluation of methods for estimating decadal stream loads, J. Hydrol., 542, 185-203, 2016.

Lee, K. H., Isenhart, T. M., Schultz, R. C., and Mickelson, S. K.: Multispecies Riparian Buffers Trap Sediment and Nutrient during Rainfall Simulations, J. Environ. Qual., 29, 1200-1205, 2000.

Li, Z., Xu, X., Yu, B., Xu, C., Liu, M., and Wang, K.: Quantifying the impacts of climate and human activities on water and sediment discharge in a karst region of southwest China, J. Hydrol., 542, 836-849, 2016.

Limbeck, R., Wentz, E., Silldorff, E., Yagecic, J., Fikslin, T., and Suk, N.: Lower Delaware River Special Protection Waters Assessment of Measurable Changes to Existing Water Quality, Round 1: Baseline EWQ (2000-2004) vs. Post-EWQ (20092011). Delaware River Basin Commission, DRBC/NPS Scenic Rivers Monitoring Program, West Trenton, NJ, USA, 588 pp., 2016.

Lizotte, R., Knight, S., Locke, M., Steinriede, W., Testa, S., and Bryant, C.: Water quality monitoring of an agricultural watershed lake: the effectiveness of agricultural best management practices, WIT Trans. Ecol. Envir., 160, 283-294, https://doi.org/10.2495/DN120251, 2012.

Mehaffey, M. H., Nash, M. S., Wade, T. G., Ebert, D. W., Jones, K. B., and Rager, A.: Linking land cover and water quality in New York City's water supply watersheds, Environ. Monit. Assess., 107, 29-44, 2005.

Meyer, L. D., Dabney, S. M., and Harmon, W. C.: Sedimenttrapping effectiveness of stiff-grass hedges, Transactions of the American Society of Agricultural and Biological Engineers, 38, 809-815, 1995.

Moatar, F., Abbott, B. N., Minaudo, C., Curie, F., and Pinay, G.: Elemental properties, hydrology, and biology interact to shape concentration-discharge curves for carbon, nutrients, sediment, and major ions, Water Resour. Res., 53, 1270-1287, 2017.

Moyer, D. L., Hirsch, R. M., and Hyer, K. E.: Comparison of Two Regression-Based Approaches for Determining Nutrient and Sediment Fluxes and Trends in the Chesapeake Bay Watershed, U.S. Geological Survey Scientific Investigations Report 2012-5244, Reston, Virginia, USA, 118 pp., 2012.

Murphy, J. and Sprague, L.: Water-quality trends in US rivers: Exploring effects from streamflow trends and changes in watershed management, Sci. Total Environ., 656, 645-658, 2019.

Murphy, J. C., Hornberger, G. M., and Liddle, R. G.: Concentrationdischarge relationships in the coal mined region of the New River basin and Indian Fork sub-basin, Tennessee, USA, Hydrol. Process., 28, 718-728, 2014.

Murphy, J. C. Farmer, W. H., Sprague, L. A., De Cicco, L. A., and Hirsch, R. M.: Water-quality trends and trend component estimates for the Nation's rivers and streams using Weighted Regressions on Time, Discharge, and Season (WRTDS) models and generalized flow normalization, 1972-2012, U.S. Geological Survey data release, https://doi.org/10.5066/F7TQ5ZS3, 2018.

Oelsner, G. P. and Stets, E. G.: Recent trends in nutrient and sediment loading to coastal areas of the conterminous U.S.: Insights and global context, Sci. Total Environ., 654, 1225-1240, 2019.

Oelsner, G. P., Sprague, L. A., Murphy, J. C., Zuellig, R. E., Johnson, H. M., Ryberg, K. R., Falcone, J. A., Stets, E. G., Vecchia, A. V., Riskin, M. L., De Cicco, L. A., Mills, T. J., and Farmer, W. H.: Water-quality trends in the Nation's rivers 
and streams, 1972-2012 - Data preparation, statistical methods, and trend results, U.S. Geological Survey Scientific Investigations Report 2017-5006, Reston, Virginia, USA, 136 pp., https://doi.org/10.3133/sir20175006, 2017.

Panthi, J., Li, F., Wang, H., Aryal, S., Dahal, P., Ghimire, S., and Kabenge, M.: Evaluating climatic and non-climatic stresses for declining surface water quality in Bagmati River of Nepal, Environ. Monit. Assess., 189, 292, https://doi.org/10.1007/s10661017-6000-9, 2017.

R Core Team: R: A language and environment for statistical computing. R Foundation for Statistical Computing, Vienna, Austria, available at: https://www.R-project.org/ (last access: 27 February 2020), 2018.

Rossi, A., Massei, N., Laignel, B., Sebag, D., and Copard, Y.: The response of the Mississippi River to climate fluctuations and reservoir construction as indicated by wavelet analysis of streamflow and suspended-sediment load, 1950-1975, J. Hydrol., 337, 237-244, 2009.

Ryberg, K. R.: Structural Equation Model of Total Phosphorus Loads in the Red River of the North Basin, USA and Canada, J. Environ. Qual., 46, 1072-1080, 2017.

Ryberg, K. R., Blomquist, J. D., Sprague, L. A., Sekellick, A. J., and Keisman, J.: Modeling drivers of phosphorus loads in Chesapeake Bay tributaries and inferences about long-term change, Sci. Total Environ., 616-617, 1423-1430, 2018.

Schottler, S. P., Ulrich, J., Belmon, P., Moore, R., Lauer, J. W., Engstrom, D. R., and Almendinger, J. E.: Twentieth century agricultural drainage creates more erosive rivers, Hydrol. Process., 28, 1951-1961, 2014.

Sprague, L. A. and Gronberg, J. M.: Relating Management Practices and Nutrient Export in Agricultural Watershed of the United States, J. Environ. Qual., 41, 1939-1950, https://doi.org/10.2134/jeq2012.0073, 2012.
Trimble, S. W. and Lund, S. W.: Soil Conservation and the Reduction of Erosion and Sedimentation in the Coon Creek Basin, Wisconsin, U.S. Geological Survey Professional Paper 1234, Washington, D.C., USA, 1982.

USEPA: National Summary of State Information under Section 305(b) and 303(d) of the Clean Water Act for Rivers and Streams, available at: https://ofmpub.epa.gov/waters10/attains_nation_cy. control\#STREAM/CREEK/RIVER (last access: 28 January 2018), 2008-2016.

Vogl, A. L. and Lopes, V. L.: Evaluating Watershed Experiments through Recursive Residual Analysis, J. Irrig. Drain. E., 136, 348-353, 2010.

Walling, D.: The Impact of Global Change on Erosion and Sediment Transport by Rivers: Current Progress and Future Challenges. The United Nations World Water Assessment Programme, Scientific Paper, Paris, France, 26 pp., 2009.

White, W. J., Morris, L. A., Pinho, A. P., Jackson, C. R., and West, L. T.: Sediment retention by forested filter strips in the Piedmont of Georgia, J. Soil Water Conserv., 62, 453-463, 2007.

Whitehead, P. G., Wilby, R. L., Battarbee, R. W., Kernan, M., and Wade, A. J.: A review of the potential impacts of climate change on surface water quality, Hydrol. Sci. J., 54, 101-123, 2009.

Williams, G. P. and Wolman, M. G.: Downstream Effects of Dams on Alluvial Rivers: U.S. Geological Survey Professional Paper 1286, https://doi.org/10.3133/pp1286, 1984.

Wohl, E.: Legacy effects on sediments in river corridors, Earth-Sci. Rev., 147, 30-53, 2015.

Wolman, M. G. and Schick, A. P.: Effects of Construction on Fluvial Sediment, Urban and Suburban Areas of Maryland, Water Resour. Res., 3, 451-464, 1967. 